Portland State University

PDXScholar

Fall 11-21-2014

\title{
Assessment of Arbuscular Mycorrhizal Symbiosis on Invasion Success in Brachypodium sylvaticum
}

Caitlin Elyse Lee

Portland State University

Follow this and additional works at: https://pdxscholar.library.pdx.edu/open_access_etds

Part of the Biology Commons, and the Plant Biology Commons

Let us know how access to this document benefits you.

\section{Recommended Citation}

Lee, Caitlin Elyse, "Assessment of Arbuscular Mycorrhizal Symbiosis on Invasion Success in Brachypodium sylvaticum" (2014). Dissertations and Theses. Paper 2108.

https://doi.org/10.15760/etd.2106

This Thesis is brought to you for free and open access. It has been accepted for inclusion in Dissertations and Theses by an authorized administrator of PDXScholar. Please contact us if we can make this document more accessible: pdxscholar@pdx.edu. 
An Assessment of Arbuscular Mycorrhizal Symbiosis on Invasion Success

in Brachypodium sylvaticum

by

Caitlin Elyse Lee

A thesis submitted in partial fulfillment of the

requirements for the degree of

Master of Science

in

Biology

Thesis Committee:

Mitchell B. Cruzan, Chair

Sarah Eppley

Daniel Ballhorn

Portland State University

2014 


\begin{abstract}
The effects that mutualistic soil biota have on invasive species success is a growing topic of inquiry. Studies of the interactions between invasive plants and arbuscular mycorrhizal fungi (AMF) have shown changes in AMF community composition, reductions in AMF associations in invasive plants, and changes in native species fitness and competitive outcomes in invasive-shifted AMF communities. These findings support the degraded mutualist hypothesis, where invasive species alter the mutualist community composition, resulting in detrimental associations with the new mutualist community for native species. Here I present two studies that examine various aspects of the arbuscular mycorrhizal fungal (AMF) mutualism in the success of a newly invasive bunchgrass, Brachypodium sylvaticum. The first chapter is a field survey of AMF associations between a native bunchgrass, Elymus glaucus and B. sylvaticum in the invaded range. The second chapter presents a test of reduced mycorrhizal dependence between invasive and native-range populations of B. sylvaticum. For the field survey, AMF colonization and spore density of root and soil rhizosphere samples from B. sylvaticum and E. glaucus from the two regions of introduction of the B. sylvaticum invasion were measured. In this survey I found lower AMF colonization and spore density in B. sylvaticum compared to the native species in the invaded ranges. The reduction in AMF associations in B. sylvaticum was predicted to be due to the evolution of reduced mycorrhizal dependence in invasive populations compared to native populations of B. sylvaticum. I tested the prediction for reduced mycorrhizal dependence by measuring the fitness gains or
\end{abstract}


losses with AMF inoculation compared to sterile conditions in both fertilized and unfertilized treatments for individuals of B. sylvaticum from each of the introduction sites in Oregon, USA and source populations from the native range in Europe. There were no differences in plant or AMF fitness between the invasive and native populations of $B$. sylvaticum. Under high nutrients the interaction between all $B$. sylvaticum plants and AMF was mutualistic. Under low nutrient treatments both $B$. sylvaticum and AMF had reduced fitness measures, suggesting a competitive interaction. Nutrient levels of inoculated unfertilized soils are similar to field conditions. It is likely that the reduction in AMF associations in B. sylvaticum observed in the field is due antagonistic interactions between AMF and B. sylvaticum. 


\section{Acknowledgements}

I thank T. Cheeke, M. LePlante, G. Marchini, R. Workman, C. Maraist, M. Williamson, E. Murphey, N. Glynn, and S. Gabriel for assistance in data collection. I thank G. Marchini, E. Webb, J. Thompson and M. Cruzan for edits to this thesis. I thank T. Cheeke and M. LePlante for training in methodology. I thank M. Cruzan for guidance in experimental design, statistical analysis, and support and guidance along my graduate school journey. I thank M. Cruzan, S. Eppley, and D. Ballhorn for serving on my committee and providing edits on this thesis. I thank my parents for their support throughout my graduate studies. My graduate studies were supported by teaching assistantships provide by Portland State University's biology department and a student coordinating assistantship for Evolution 2013 provided by the Society for the Study of Evolution. The biology department at Portland State University and a merit award from the Botanical Society of America in 2010 provided the funding for research reported in this thesis. 
Table of Contents

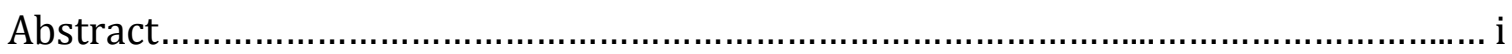

Acknowledgements.................................................................................... ii

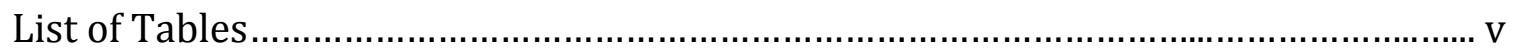

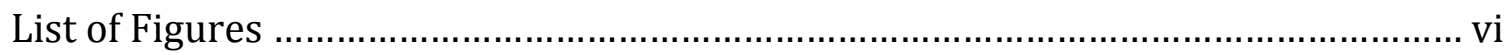

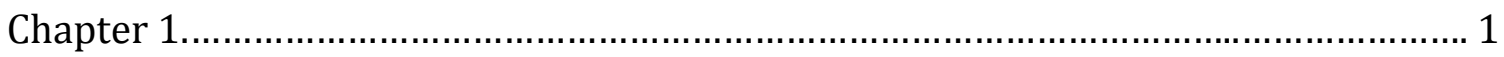

A field survey of arbuscular mycorrhizal fungal abundance between invasive Brachypodium sylvaticum and native Elymus glaucus

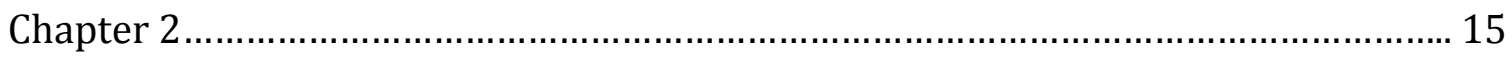

The effects of fertilization on arbuscular mycorrhizal symbiosis in Brachypodium sylvaticum from native and invasive ranges

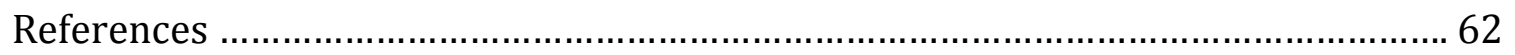




\section{List of Tables}

Table 1.1.

Population code, location, and global positioning system (GPS) coordinates for three populations in Corvallis and Eugene.

Table 2.1.

Population code, location, and global positioning system (GPS) coordinates for three populations in Corvallis, Eugene, and Europe.

Table 2.2.

ANCOVA table for the effect of harvest date, region, fertilization, region*fertilization, inoculation, region*inoculation, fertilization*inoculation, region*fertilization*inoculation, and initial plant weight on final dry mass (biomass).

Table 2.3.

ANCOVA table for the effect of harvest date, region, fertilization, region*fertilization, inoculation, region*inoculation, fertilization*inoculation, region*fertilization*inoculation, and initial plant weight on final shoot dry mass.

Table 2.4.

ANCOVA table for the effect of region, fertilization, region*fertilization, inoculation, region*inoculation, fertilization*inoculation, region*fertilization*inoculation, and initial plant size on plant size at all harvests.

Table 2.5 .

ANCOVA table for the effect of region, fertilization, region*fertilization, inoculation, region*inoculation, fertilization*inoculation, region*fertilization*inoculation, initial plant size, and average specific leaf area on chlorophyll content at all harvests.

Table 2.6.

ANCOVA table for the effect of region, fertilization, region*fertilization, chlorophyll content of the host plant at 91 days and initial plant weight on percent roots colonized by arbuscular mycorrhizal fungi for all harvests.

Table 2.7.

ANCOVA table for the effect of region, fertilization, region*fertilization, inoculation, region*inoculation, fertilization*inoculation, region*fertilization*inoculation, total \%arbuscules and initial plant weight on spore density for 90 and 120 day harvests. 


\section{List of Figures}

Figure 1.1.

Population locations for sampled B. sylvaticum and E. glaucus in Corvallis and Eugene.

Figure 1.2.

Percent AMF colonization of plant roots for B. sylvaticum and E. glaucus collected from Corvallis and Eugene.

Figure 1.3.

Percent of assayed roots containing arbuscules for B. sylvaticum and E. glaucus plants collected from Corvallis and Eugene.

Figure 1.4.

Spore density (spores/g soil) of the rhizosphere of B. sylvaticum and $E$. glaucus plants from Corvallis and Eugene.

Figure 2.1. .53

Population locations of B. sylvaticum individuals from Corvallis, Eugene and Europe.

Figure 2.2.

Final dry mass of fertilized and unfertilized inoculated and sterile plants for all harvests $(\mathrm{p}<0.001)$. Error bars represent standard error.

Figure 2.3.

Final shoot dry mass of fertilized and unfertilized inoculated and sterile plants for all harvests $(\mathrm{p}<0.001)$. Error bars represent standard error.

Figure 2.4.

Plant size over 124 days of all treatments averaged across all harvests.

Figure 2.5. .57

Chlorophyll meter readings over 124 days for all treatments averaged over all harvests.

Figure 2.6. .58

Percent colonization by arbuscular mycorrhizal fungi for inoculated and sterile plants for 120 day harvest and averaged for all harvests. 
Figure 2.7.

Percent colonization by arbuscular mycorrhizal fungi for fertilized and unfertilized for each region of plants for 120 day harvest and averaged for all harvests.

Figure 2.8. .60

The change in spore densities between fertilized and unfertilized, sterile and inoculated plants from Corvallis, Eugene, and Europe for the 90 day harvest.

Figure 2.9. .61

Arbuscular mycorrhizal spore density of soil collected from experimental pots for plants at the 90 day harvest for all treatments. 


\title{
Chapter 1
}

A field survey of arbuscular mycorrhizal fungal abundance between invasive Brachypodium sylvaticum and native Elymus glaucus

\begin{abstract}
Invasion biology has recently begun to acknowledge the role of mutualisms in invasion success. Arbuscular mycorrhizal fungi (AMF) are one of the most widespread and oldest mutualisms with plants. Recent research has shown that invasive species are able to alter arbuscular mycorrhizal communities, which may aid in invasion success. I set out to collect evidence for a shift in arbuscular mycorrhizal fungal interactions with a newly invasive species, Brachypodium sylvaticum, to allow for further research into how associations with AMF impact the invasion success of this species. AMF colonization and spore densities of ten individuals of B. sylvaticum and a native species, Elymus glaucus, were assessed for six locations in local regions near the two introduction sites (Eugene and Corvallis) of the invaded range in Oregon, US. B. sylvaticum had reduced levels of arbuscular mycorrhizal colonization compared with E. glaucus in both introduction sites. $B$. sylvaticum had reduced spore densities in Corvallis, but not in Eugene, suggesting that differences in associations with arbuscular mycorrhizal fungi between the two introductions may be impacting the invasion success of B. sylvaticum. Further tests of invasion-mutualism hypotheses are proposed to better understand the role that the arbuscular mycorrhizal mutualism has on invasion success of $B$. sylvaticum.
\end{abstract}




\section{Introduction}

Interest in factors influencing the success of species establishment and proliferation into novel habitats is increasing for both the prevention and eradication of ecosystem-damaging invasive species. Studies of invasion success are relevant to understanding how species may be able to shift their ranges as climate change shifts optimum habitats of species to new ranges. Many biotic and abiotic interactions have been shown to impact species establishment and success in novel ranges (Richardson, et al. 2000; Hallett 2006; Mitchell, et al. 2006; Richardson and Pysek 2006). Competitive and parasitic interactions have been the main focus for biotic interactions in the early years of invasive species ecology (Callaway, et al. 2008), but recent attention has included mutualistic interactions (Marler, Zabinski and Callaway 1999; Klironomos 2002a, b; Callaway, et al. 2004). The growing body of research shows contradicting influences of mutualisms on species establishment and spread into novel habitats, with some species being dependent on mutualisms for establishment (Dunstan, et al. 1998; Richardson, et al. 2000; Porter, et al. 2011) while other mutualists aid communities in resisting invasion (van der Heijden, et al. 2006). Mutualists can also impact competitive outcomes and parasitic defenses resulting in a need for the integration of mutualistic interactions into previous research on competitive and parasitic influences on invasive species success (Mitchell, et al. 2006; Catford, et al. 2009). 
Plant associations with mutualistic soil fungi, termed mycorrhizae, are one of the most widespread and oldest mutualisms on earth (Wang and Qiu 2006; Smith and Read 2008). Mycorrhizal associations improve plant fitness through nutrient acquisition in exchange for fixed carbon, but fitness gains for each mutualist vary across different types of mycorrhizae (Smith and Read 2008). Arbuscular mycorrhizal fungi (AMF), in the phylum Glomeromycota (Schussler, et al. 2001), are the most common type of mycorrhizae, associating with the majority of mycorrhizal plant families (Wang and Qiu 2006). AMF are also the least specific, as fungi are obligate symbionts and plants are most often facultative hosts (Smith and Read 2008). Fitness benefits to plants with AMF are fungal-species specific, with single AMF species benefiting some species of plants more than others (Pearson and Jakobsen 1993; Klironomos 2003; Hoeksema, et al. 2010; Mangan, et al. 2010). Due to differences in benefits exchanged between individual species of AMF and plants and the unbalanced interaction between obligate AMF and facultative plant hosts, plants are expected to have control over carbon allocation to more beneficial AMF (Grman 2012; Correa, et al. 2014).

The ability of plants to selectively allocate carbon favors more beneficial AMF species over time (Zhang, et al. 2010). Diverse communities of plants, therefore, support more diverse communities of AMF (van der Heijden, et al. 2006; Zhang, et al. 2010). Invasive species have been shown to change AMF community compositions (Cumming and Kelly 2007; Sanon, et al. 2009; Zhang, et al. 2010; Kulmatiski and Beard 2011; Velazquez and Cabello 2011; Sanon, et al. 2012), but the interaction 
between AMF and invasive species vary (Meiman, et al. 2006). Some invasive species receive increased benefits with AMF from the introduced range compared to the native range (Zhang, et al. 2010; Yang, et al. 2013). The enhanced mutualism hypothesis predicts that the increased benefits received by non-native species from mutualists in the introduced range facilitate species invasions (Richardson, et al. 2000; Reinhart and Callaway 2006). Conversely, many invasive plants have been shown to reduce AMF abundances and the resulting changes in AMF communities negatively impact native species (Callaway, et al. 2008; Vogelsang and Bever 2009; Meinhardt and Gehring 2012; Wilson, et al. 2012). The observed degradation of the AMF symbiosis with native species in invaded ranges has been termed the degraded mutualist hypothesis (Schlaepfer, et al. 2005; Reinhart and Callaway 2006; van der Putten, et al. 2007; Vogelsang and Bever 2009).

To test the impact of the AMF mutualism on invasive species success and the reduction in native species fitness due to invasive-induced shifts in AMF communities, differences in AMF associations in an invasive species compared to native species in the invaded range must be first be demonstrated. If there are no differences in species abundances or diversity in invaded ranges, it is unlikely that invasive species' associations with AMF will facilitate the displacement of native species.

In this study I set out to survey differences in AMF root colonization and spore abundances in the rhizospheres of a newly invasive bunchgrass, Brachypodium sylvaticum (Hudson) Beauv. (slender false brome), and a neighboring native species, 
Elymus glaucus Buckley (blue wild-rye), to obtain an initial indication of whether the AMF symbiosis with B. sylvaticum may be a factor affecting the species' invasion success. B. sylvaticum was introduced in two separate regions, Corvallis and Eugene, OR, independently in the 1920s and began range expansion sometime in the 1980 s (Chambers 1966; Rosenthal, et al. 2008). Genetic analysis indicates Corvallis populations are the source for the majority of the peripheral populations along the leading edge of the expanding range (Ramakrishnan, et al. 2010). B. sylvaticum is found predominantly in shaded forest understory and along roads (Rosenthal, et al. 2008; Ramakrishnan, et al. 2010). Due to variation in plant-soil feedbacks across species ranges, Reinhart and Callaway (2006) suggest targeted sampling of known ecologically important sites, such as founder sites of invasions. Ten plants of both $E$. glaucus and B. sylvaticum were sampled for root colonization by AMF and rhizosphere spore densities from populations in Corvallis and Eugene to address the following questions:

1. Is there a difference in AMF colonization and spore abundance in $B$. sylvaticum compared to a native species in the invaded range?

2. Are there differences in AMF colonization and spore densities between the two introduction sites for each species?

I expected to find a reduction in AMF colonization and spore densities in $B$. sylvaticum compared to E. glaucus because the majority of studies examining AMF associations with invasive plants have shown decreased AMF associations in invasive species (Callaway, et al. 2008; Seifert, et al. 2009; Vogelsang and Bever 
2009; Sanon, et al. 2012), and the degraded mutualist hypothesis is expected in AMF symbioses (Reinhart and Callaway 2006). Due to the observation that AMF interactions shift across species' ranges (Ji, et al. 2012) and differences in the AMF symbiosis can be based on genetic differences in a species (Barker, et al. 2002;

Linderman and Davis 2004; Gehring, et al. 2006; An, et al. 2010; Yang, et al. 2013), there are likely differences in AMF colonization and spore abundance in $B$. sylvaticum between the two introduction sites, though these differences are not expected to change the comparison between B. sylvaticum and native E. glaucus.

\section{Methods}

\section{Field Survey}

To test for a reduction in AMF associations in Brachypodium sylvaticum compared to native species, plant roots and rhizosphere soil of both native Elymus glaucus and invasive B. sylvaticum were sampled in the regions of Eugene and Corvallis Oregon, USA. Three populations were sampled from each region (E4, E6 and E9 in Eugene and C2, C3 and C5 in Corvallis) (Figure 1.1; Table 1.1 for Global Positioning System (GPS) coordinates for each population). The Corvallis and Eugene regions were chosen because they are the known locations of primary introduction in Oregon (Rosenthal, et al. 2008). Populations were either along roadsides (E6, E9, C2 and some plants from C5), mainly comprised of rocky soil (personal obs.), or in forested areas (E4, C3 and some plants from C5) with soil comprised largely of clay with a layer of detritus and moss up to ten centimeters 
thick on top (personal obs.). Ten individuals of B. sylvaticum were sampled for all six populations from sites with a high density of B. sylvaticum and little to no presence of native species, totaling 60 individuals sampled. Ten individuals of E. glaucus were collected from adjacent sites containing little to no invasive individuals from five populations (E4, E6, C2, C3 and C5) due to an absence of native individuals at E9, totaling 50 individuals sampled. Individuals sampled were at least one meter apart where possible and were selected only if they could be identified as a single individual. Roots were collected by digging to a depth of $40 \mathrm{~cm}$ and separating roots from shoots; rhizosphere soil was shaken from roots and collected. Samples were stored at $4^{\circ} \mathrm{C}$ until mycorrhizal colonization and spore abundance could be assessed.

\section{Assesment of Mycorrhizal colonization}

Roots were rinsed with tap water before fine roots were sampled at three random locations and placed in histocassettes (VWR, West Chester, PA). Roots were cleared with $10 \% \mathrm{KOH}$, followed by a 30 second soak in $5 \%$ bleach, neutralized in 2\% $\mathrm{HCl}$, and stained with $0.05 \%$ Trypan blue, as described by Phillips and Hayman (1970). Stained roots were cut into approximately $1 \mathrm{~cm}$ segments and placed on microscope slides in rows in lactoglycerol. A minimum of $50 \mathrm{~cm}$ of root was assessed for mycorrhizal structures (hyphae, arbuscules, and vesicles) and percent AMF colonization using the slide-intersect method (McGonigle, et al. 1990). 


\section{Spore extraction and quantification}

To quantify spore abundance in plants collected from the field survey, $50 \mathrm{~g}$ rhizosphere soil was agitated with 5\% Alconox solution, rinsed through three sieves of $515.62 \mu \mathrm{m}, 248.92 \mu \mathrm{m}$, and $38 \mu \mathrm{m}$ pore size, stacked largest to smallest, with tap water, breaking up any remaining clumps of soil by hand. Contents of the $248.92 \mu \mathrm{m}$ and $38 \mu \mathrm{m}$ sieves were mixed with Ringer's solution and centrifuged at $2000 \mathrm{rpm}$ for 4 min. Supernatent was drained, and the remaining soil was re-suspended in 1.4 M sucrose solution and centrifuged at $2000 \mathrm{rpm}$ for $4 \mathrm{~min}$. Supernatant was retrieved and rinsed with tap water through the $38 \mu \mathrm{m}$ sieve (modified from Gerdemann and Nicolson (1963)). The resulting contents in the $38 \mu \mathrm{m}$ sieve were vacuum filtered onto $0.45 \mu \mathrm{m} 47 \mathrm{~mm}$ white, gridded filter papers (Pall Corporation, Ann Arbor, MI), and spores were visualized and counted at 50X magnification for the whole extraction (as compared to ten contiguous squares to estimate spore density as in MeKenney and Lindsey (1987)). Only smooth, spherical, and translucent spores ranging in color with evidence of hyphal attachments present were counted to ensure proper spore identification. This methods underestimates spore density, as there is large variation in spore shape and not all live spores retain their hyphal attachments (Meier and Charvat 1992). Spore counts were divided by soil sample weight to give spore density (spores per gram soil). 


\section{Statistical analysis}

Differences in the abundance of AMF structures in roots (hyphae, arbuscules, vesicles and total percent roots colonized) and soil spore densities (spore/g soil) between species were analyzed using a general linear regression (GLM) procedure in SAS (version 9.2). Percent hyphae, arbuscules, vesicles and spore density were log transformed to normalize the distributions. For AMF colonization, species (E.

glaucus and B. sylvaticum) and region (Eugene and Corvallis) were treated as fixed effects, and population nested within region and species was treated as a random effect. For spore densities, the same variables used for fixed and random effects for AMF colonization were used and percent roots containing arbuscules was added as a covariate, as arbuscules are the site of carbon acquisition for AMF and are expected to be correlated with spore production (Smith and Read 2008).

\section{Results}

\section{Arbuscular mycorrhizal fungal colonization}

Total percent colonization of roots by arbuscule mycorrhizal fungi was significantly higher in E. glaucus $(35.7 \% \pm 14.6$; mean \pm std. dev.) compared to $B$. sylvaticum $\left(25.6 \% \pm 11.1 ; \mathrm{F}_{10 / 91}=8.04, \mathrm{p}=0.007\right)$. Overall, percent roots colonized was higher for plants from Eugene compared to plants from Corvallis $\left(\mathrm{F}_{10 / 91}=8.04\right.$, $\mathrm{p}=0.03$; figure 1.2), with E. glaucus significantly more colonized than B. sylvaticum in both regions. There was significant variation among populations within region within species ( $\mathrm{p}=0.029)$. Percent roots containing arbuscules was significantly 
higher in all plants from Eugene $(3.4 \% \pm 0.7)$ compared to plants collected from Corvallis $(2.8 \% \pm 0.8)\left(\mathrm{F}_{10 / 91}=3.95, \mathrm{p}=0.01\right.$, figure 1.3$)$, with marginally significant differences among populations within region within species $(\mathrm{F} 10 / 91=3.95, \mathrm{p}=0.057)$. Differences between species in percent content of hyphae $\left(\mathrm{F}_{10 / 90}=1.61, \mathrm{p}=0.16\right)$ and vesicles $\left(\mathrm{F}_{10 / 91}=1.25, \mathrm{p}=0.86\right)$ were not significant. Additionally, there were no significant differences between regions for percent root content of hyphae $\left(\mathrm{F}_{10 / 91}=1.61, \mathrm{p}=0.83\right)$ and vesicles $\left(\mathrm{F}_{10 / 91}=1.25, \mathrm{p}=0.44\right)$.

Spore density

There were no significant differences between regions or species when analyzed separately for spore densities in rhizosphere soil. However, there was a significant difference for the species by region interaction $\left(\mathrm{F}_{11 / 52}=3.56, \mathrm{p}=0.046\right)$, with E. glaucus having higher spore densities than B. sylvaticum in Corvallis and the reverse in Eugene (figure 1.4).

\section{Discussion}

Decreased mycorrhizal colonization and spore abundance was found in $B$. sylvaticum compared to native E. glaucus, providing initial evidence that AMF interactions in B. sylvaticum are affecting this species' invasion success. A number of other studies have demonstrated differences in AMF colonization and community composition between native and invasive species in invaded ranges (Hawkes, et al. 2006; Sanon, et al. 2012; Endresz, et al. 2013). The reduction in AMF colonization in 
B. sylvaticum compared to E. glaucus suggests a negative interaction in the $B$. sylvaticum-AMF symbiosis. The differences in AMF spore densities in rhizosphere soil of B. sylvaticum compared to E. glaucus were reversed between Eugene and Corvallis. AMF spore densities were decreased in B. sylvaticum compared to $E$. glaucus in Corvallis, but increased in Eugene, indicating a difference in the fitness outcomes between AMF and B. sylvaticum. The occurrence of the difference between the two introduction sites suggests that AMF associations may be affecting $B$. sylvaticum's ability to spread, since Corvallis is the source of most of the peripheral populations along the expanding edge of the invasion. Additional experiments are needed to demonstrate a negative interaction between B. sylvaticum and the AMF community and how this may be impacting invasion success.

A negative interaction between AMF and B. sylvaticum would lead to a degradation of the AMF community and likely impact native species. Various studies have found decreases in AMF colonization and plant growth of native species when grown in soils around invasive species (Zhang, et al. 2007; Vogelsang and Bever 2009; Meinhardt and Gehring 2012; Wilson, et al. 2012). Zhang et al. (2010) demonstrated both a shift in a manipulated AMF community towards more beneficial species for invasive Solidago canadensis and decreased growth of native Kummerawia striata when grown in the invasive-shifted AMF community. In a field study, Sanon et al. (2009) found reduced AMF density in invaded regions compared to uninvaded regions coupled with reduced growth of a native species in invaded soils compared to uninvaded soils. Further study to demonstrate changes in the 
AMF community composition between invaded and adjacent uninvaded sites of $B$. sylvaticum and the impact invaded AMF communities have on native species growth are other avenues of research to test the degraded mutualist hypothesis.

Changes in AMF communities can have impacts on the competitive outcomes between invasive species and neighboring native species. AMF associations have been shown to ameliorate growth differences in competing species, as well as give competitive advantage or disadvantage to a competing species. Zhang et al. (2010) demonstrated an interspecific competitive advantage for invasive Solidago canadensis when grown with AMF communities previously grown with $S$. canadensis compared to AMF communities associated with the native Kummerowia striata or neither species. However, competitive outcomes between invasive and neighboring native plants are not always increased with AMF colonization. Callaway et al. (2004) found varied differences in competitive outcomes for spotted knapweed (Centaurea malculosa) were competitor species dependent when grown with compared to without AMF. A change in AMF species composition and corresponding competitive advantage for an invasive species would be needed to support the degraded mutualist hypothesis, as was seen in Zhang et al. (2010) study.

The reduction of AMF associations observed in B. sylvaticum may also be indicative of a reduction in AMF dependency in invasive populations. Decreases in AMF associations coupled with no change or increases in growth of species from invasive populations compared to native populations has been termed reduced mycorrhizal dependence (Seifert, et al. 2009). Seifert et al. (2009) found reduced 
colonization and increased growth of invasive populations of St. John's wort (Hypericum perforatum) compared to native populations when planted in invasive range soils. The difference in spore densities in B. sylvaticum between Eugene and Corvallis, coupled with increases in arbuscule formation in the roots may indicate a difference in B. sylvaticum's ability to regulate carbon loss to AMF between the two genetically distinct introduction sites. Previous research has shown no differences in AMF colonization based on genotypes and the quantity of arbuscules in roots has not been correlated to carbon allocation to AMF (Johnson, et al. 2010; Karasawa, et al. 2012). However plants have been shown to vary in their ability to control carbon allocation to AMF (Grman 2012), and genetic variation is necessary for evolution to occur (An, et al. 2010; Yang, et al. 2013). It is therefore possible that Eugene populations of B. sylvaticum are less able to regulate the negative interactions with $\mathrm{AMF}$, and the resulting decrease in plant fitness may be an explanation for the lack of Eugene populations' range expansion. The incidence of both reduced colonization and spore densities in Corvallis populations may indicate the evolution of reduced mycorrhizal dependence in this introduction and the reduction in mycorrhizal dependence may be aiding Corvallis populations in range expansion. To test for the evolution of reduced mycorrhizal dependence, the growth response and AMF colonization of native and invasive populations of B. sylvaticum exposed to soil microbial communities from the invaded range must be assessed. The use of populations from each introduction site of $B$. sylvaticum would be important, as 
differences in AMF associations between the introductions sites have been shown here.

The reduction in AMF colonization and, to some extent, spore densities of $B$. sylvaticum compared to a native species, E. glaucus in the invaded ranges provides an initial indication that AMF associations may be affecting the invasion success of $B$. sylvaticum. Being able to take advantage of B. sylvaticum while in the early stages of range expansion will add an additional level of understanding for the processes that lead to the documented outcomes after invasive spread. Continued study of this and other systems is important for a better understanding of the role that mutualisms play in invasion ecology, for both invasion success and restoration efforts. 


\title{
Chapter 2
}

The effects of fertilization on arbuscular mycorrhizal symbiosis in Brachypodium sylvaticum from native and invasive ranges

\begin{abstract}
Species interactions shape community structures and productivity. The introduction of novel plants often reduces mutualistic soil biota diversity and abundances, resulting in degraded mutualisms with native species, drastically altering communities. The degradation of mutualistic soil biotic communities can be caused by negative interactions between resident mutualists and novel symbionts. Successful invasive species are expected to have evolved a reduced dependence on soil mutualists to overcome the negative interaction. Here I examine the interaction between a newly invasive bunchgrass, Brachypodium sylvaticum, and mutualistic soil fungi, arbuscular mycorrhizal fungi (AMF), for invasive and source populations of the grass to test for negative interactions with AMF in source populations and reduced dependence on AMF in invasive populations. Clones of individuals of $B$. sylvaticum from both invasion introduction sites and source populations of the invasion were grown with and without intact microbial communities from the invaded region with and without fertilization. Growth, root colonization by AMF, and AMF spore abundances were measured. Plant growth was improved by AMF colonization in the fertilized treatment and reduced with AMF colonization in the unfertilized treatment. AMF colonization increased but spore densities were reduced in the unfertilized treatment. There were no differences in growth between
\end{abstract}


the invasive and source populations of B. sylvaticum. The negative interaction between B. sylvaticum and invaded region AMF is competitive, indicated by the reduction in fitness measures for both partners. This negative interaction is likely leading to the reductions in AMF colonization and spore densities compared to natives in the invaded range shown in a previous study. Reduced mycorrhizal dependency in B. sylvaticum has not yet evolved in the invaded range, but is expected given the antagonistic interaction.

\section{Introduction}

The global spread of invasive species is incurring large economic and ecological costs by impacting native species diversity, altering plant community composition, and reducing productivity of agricultural systems and rangelands (Dantonio and Vitousek 1992; Mack, et al. 2000; Pimentel, et al. 2005; van der Putten, et al. 2007). Understanding the factors, both biotic and abiotic, affecting establishment and range expansion of invasive species is important for management practices, including prevention of species introductions and spread, and restoration of invaded ranges (Richardson, et al. 2000; Schlaepfer, et al. 2005; Hallett 2006; Mitchell, et al. 2006; Richardson and Pysek 2006). New attention is being paid to the effects of mutualisms in invasions, partially due to recent research on interactions with below ground microbial communities (Callaway, et al. 1999; Marler, Zabinski and Callaway 1999; Marler, Zabinski, Wojtowicz, et al. 1999; Klironomos 2002a, b). Multiple hypotheses have been proposed to explain the impacts mutualistic 
interactions have on invasive species: 1) the mutualist hypothesis (co-invasion hypothesis) explains the need for the presence of a mutualist for the establishment of an invasive (Porter, et al. 2011), 2) the enhanced mutualist hypothesis explains that invasive success is due to better mutualists in the invaded range compared to the native range (Richardson, et al. 2000; Reinhart and Callaway 2006), and 3) the degraded mutualist hypothesis (mutualism disruption hypothesis) predicts shifts in communities of mutualists due to invasion will restrict native and promote more invasive establishment(Schlaepfer, et al. 2005; Reinhart and Callaway 2006; van der Putten, et al. 2007).

Support for each of the invasion-mutualism hypotheses has been found in studies of below ground mutualistic soil biota. For instance, the establishment and invasions of Pinus ssp. in Australia were reliant on the introduction of associated ectomycorrhizal species from native regions in the northern hemisphere, lending support for the mutualist hypothesis (Dunstan, et al. 1998; Richardson, et al. 2000). Evidence for the enhanced mutualist hypothesis was contributed by Yang et al. (2013) who found increased plant performance of Chinese tallow (Triadica sebifera) with invasive range soil biota compared to native range soil biota. Studies have shown shifts in arbuscular mycorrhizal community composition in invaded ranges compared to native species in the invaded ranges, coupled with reduced infection potential, supporting the degraded mutualist hypothesis (Callaway, et al. 2008; Endresz, et al. 2013). Studies of the impacts of mutualistic soil fungi, particularly arbuscular mycorrhizal fungi (AMF) on plant invasions are becoming more common, 
and our understanding of relationships between plants and fungi more variable. The pervasiveness of the AMF symbiosis, with $92 \%$ of plant families containing mycorrhizal hosts and the majority of these being arbuscular mycorrhizal hosts (Wang and Qiu 2006; Smith and Read 2008), makes the continued study of the reciprocal impacts between AMF and invasive plants an important facet for understanding invasion success and impacts on diversity and productivity of ecosystems.

Arbuscular mycorrhizal fungal interactions with plants are ubiquitous and characterized by intraradical infection by arbuscular mycorrhizal fungi (phylum Glomeromycota)(Schussler, et al. 2001) of plant roots for the exchange of limiting soil nutrients, predominately phosphorus but to a lesser extent nitrogen and other minerals, for photosynthates (Bethlenfalvay, et al. 1991; He, et al. 2003; Cheng and Baumgartner 2004; Smith and Read 2008; Correa, et al. 2014; Fellbaum, et al. 2014). AMF are obligate and specialized symbionts, while the majority of plant host species are generalists and facultative (Grman, et al. 2012). All species to species interactions have varied fitness outcomes for each partner: neutralism $(0,0)$, amensalism $(0,-)$, commensalism $(0,+)$, competition $(-,-)$ mutualism $(+,+)$, and parasitism $(-,+)$ ( 0 denotes no effect, - denotes a fitness cost, and + denotes a fitness gain)(Morcom and Woelkerling 2000; Richardson, et al. 2000). Arbuscular mycorrhizal symbiosis has traditionally been classified as a mutualism. However, due to the obligate need of AMF to colonize a facultative host for growth and reproduction, there can be an imbalance in fitness outcomes for each partner 
(Bronstein 1994; Schwartz and Hoeksema 1998). These lopsided fitness gains result in an unstable mutualism, where, under high nutrient conditions AMF become parasitic, acquiring photosynthates when plants are not in need of any additional nutrients (Grman, et al. 2012). The variation in fitness outcomes for each partner has been termed the mutualism-parasitism continuum (Johnson, et al. 1997; Hoeksema, et al. 2010; Johnson and Graham 2013).

Perhaps more important than nutrient conditions of the soil is the speciesspecific plant response to AMF species, where each plant species receive the most benefit from different species of AMF (Pearson and Jakobsen 1993; Klironomos 2003; Mangan, et al. 2010). Plants are predicted to be able to mediate carbon loss or prevent infection by less beneficial AMF species as a mechanism for maintaining the mutualistic interaction over evolutionary time (Grman, et al. 2012). There has been some documentation of plant mediation of carbon loss, though plants' effectiveness at mediation varies across species (Grman 2012). It is unclear as to whether all plants share the ability to regulate carbon loss, but if so, plants can select for more beneficial mutualists through carbon allocation. AMF community composition would then be partially dependent on plant species composition (Callaway, et al. 2004) in addition to abiotic factors, such as soil chemistry (Ji, et al. 2012) and nutrient availability (Kiers, et al. 2011; Antunes, et al. 2012).

There is support for the degraded mutualist hypothesis in studies of many invasive plants and AMF. Differences in AMF community composition between invaded and uninvaded ranges have been shown (Sanon, et al. 2009; Zhang, et al. 
2010; Kulmatiski and Beard 2011; Velazquez and Cabello 2011; Sanon, et al. 2012), including changes in AMF community composition in soils and roots after only a few growing seasons (Jordan, et al. 2012). Changes in AMF community composition have been linked to reduced establishment of natives in invaded soils (legacy effects) (Grman and Suding 2010; Zhang, et al. 2010; Jordan, et al. 2011). Several invasive species have reduced mycorrhizal colonization compared to native species of the invaded range, though to my knowledge no study has tested for a decrease in AMF fitness due to reduced colonization. Decreases in plant growth responses to AMF between invasive and native populations of an invasive species has been termed reduced mycorrhizal dependence (Seifert, et al. 2009). An evaluation of AMF fitness shifts is necessary to test the degraded mutualist hypothesis, since shifts in AMF community composition are dependent on changes in AMF fitness outcomes. Here, I provide a more complete test for one aspect of the degraded mutualist hypothesis, reduced mycorrhizal dependence, in a newly invasive perennial bunchgrass, Brachypodium sylvaticum (Hudson) Beauv. (slender false brome), by quantifying plant and fungal fitness in invasive and native plants pairings with invaded range soil microbial communities.

Brachypodium sylvaticum is a newly invasive bunchgrass to Oregon, USA that is native to Eurasia and Northern Africa. It was first recorded in Oregon in 1939 (Chambers 1966), and was fully naturalized by 1966 (Chambers 1966; Kaye and Blakeley-Smith 2006) . This species originated from multiple locations in Western Europe and possibly Northern Africa, and was introduced into Oregon through two 
separate introduction events in Eugene and Corvallis (Rosenthal, et al. 2008). In both its native and invasive ranges B. sylvaticum can be found in both shaded forest understory and sunny open meadows (Holten 1980; Aarrestad 2000; Kirby and Thomas 2000; Rosenthal, et al. 2008), with Oregon populations occurring predominately in shaded forest understory (Rosenthal, et al. 2008). B. sylvaticum is listed as a quarantined invasive species in Washington, Oregon, and California (CDFA 2009; NWCB 2009; ODA 2009) and has been identified in Missouri, Virginia, and most recently in Ontario, Canada (Roy 2010; Miller, et al. 2011). Molecular analysis of peripheral populations along the leading edge of the invasion indicates that the Corvallis introduction is responsible for the majority of the invasion in Oregon (Ramakrishnan, et al. 2008).

B. sylvaticum is an ideal species for studying the effects of AMF colonization on invasion success because the source populations for the invasion are known (Rosenthal, et al. 2008), it is in the process of range expansion, and reductions in AMF colonization and spore abundances compared to a native heterospecific species have been demonstrated (Lee). Additionally, the assessment of AMF interactions in B. sylvaticum will add to the growing body of literature on the effects of AMF in agricultural systems, since B. sylvaticum is being developed as a model system for testing biotechnology for agriculture (Steinwand, et al. 2013) and its close relative Brachypodium distachyon is a genomics and more recently a pathosystem model species for grasses and cereals (Draper, et al. 2001; Brkljacic, et al. 2011; Mur, et al. 2011; Peraldi, et al. 2014). 
To assess levels of mycorrhizal dependence in B. sylvaticum, a manipulated greenhouse experiment was performed to quantify shifts in fitness gains for plants and AMF for the invasive and native-range populations. Quantifying AMF fitness is necessary for determining the plant's decreased participation in the symbiosis. Previous research on reduced dependence on AMF in invasive plants has exclusively used AMF colonization to quantify a reduction in benefit received by AMF (Seifert, et al. 2009). However, research has shown carbon allocation is not correlated with colonization (Karasawa, et al. 2012). Therefore, quantifying AMF spore production will be a better measure of AMF fitness. Individuals from both invasive introductions and the source populations in Europe were grown with and without AMF inoculum from invaded range soils under high and low nutrient treatments. The high nutrient treatment was used as a benchmark for how parasitic the interaction could be, since the AMF-plant symbiosis is expected to be most parasitic under high nutrient conditions (Johnson 1993; Neuhauser and Fargione 2004). This should allow for a more complete assessment of plant fitness gains and fungal fitness losses in field conditions (low nutrient treatment). This experiment was replicated over three harvest dates to capture the change in the AMF-plant interaction over time, since there are known differences in AMF colonization and sporulation based on plant life stage (Douds and Chaney 1982; Panwar, et al. 2011; Velazquez and Cabello 2011). I set out to test three questions: 
1. Is there a reduction in the fitness of plants from the native range compared to the invasive range, particularly under high nutrient treatments (evidence of reduced mycorrhizal dependence)?

2. Is there a reduction in fungal fitness due to regional origin of B. sylvaticum?

3. Does the interaction between AMF and B. sylvaticum change over plant life stages?

Decreased growth of native plants with AMF colonization compared to invasive plants is expected if invasive populations have evolved reduced mycorrhizal dependence. This difference should be greater in the high nutrient treatment, where parasitism by AMF is expected. AMF spore production should be reduced with invasive plants compared to native plants in both nutrient treatments. Differences in the fitness outcomes of the AMF interaction are expected across the three harvest dates.

\section{Methods}

Experimental Design

Plants utilized for this study were collected as seed from multiple populations in and near the invasion introduction sites (Corvallis, OR and Eugene OR, USA) and acquired from the US Department of Agriculture (USDA) for native sites, grown and maintained in the research greenhouse at Portland State University (Portland, OR, USA) for three to five years under the following conditions: the temperature varied between $15.5^{\circ} \mathrm{C}$ and $26.7^{\circ} \mathrm{C}$, and a mix of sunlight and 20 
$\mathrm{Mw} / \mathrm{cm}^{2}$ to $40 \mathrm{Mw} / \mathrm{cm}^{2}$ of supplemental light were provided between $7 \mathrm{am}$ and $7 \mathrm{pm}$ with 1000W HID bulbs (Philips Co., NV, USA). Three populations for each range (Corvallis, Eugene, and Europe) were selected based on replicate numbers of maternal families available for the study (population names and global positioning coordinates (GPS) available in table 2.1; figure 2.1). Additionally, the three European populations (England, Italy, and Greece) were selected from estimated source populations of the invasion introduction based on microsatilite markers (Rosenthal, et al. 2008).

To assess the level of cooperation between B. sylvaticum and AMF, clones of three individuals per population were exposed to one of four treatments with +/AMF inoculation and +/- addition of 3-3-3 NPK fertilizer (Dr. Earth Co., Winters, CA, USA), resulting in +AMF/unfertilized, $-\mathrm{AMF} /$ unfertilized, $+\mathrm{AMF} /$ fertilized, and AMF/fertilized. Plants with -AMF treatment were used as a control for estimating overall costs/benefits on plant growth (AMF response). The addition of fertilizer was used to attempt to capture a more precise assessment of AMF response along the mutualism parasitism continuum. The use of a standard should allow for a greater understanding of the AMF symbiosis in both greenhouse and natural experiments.

To assess the change in the AMF relationship with B. sylvaticum over time, the experimental design was replicated three times for harvest at successive time intervals: 60,90 and 120 days. Seasonal variations in colonization rates and spore production have been shown (Panwar, et al. 2011), with AMF colonization declining 
and sporulation typically occurring upon flowering of the host plant (Smith and Read 2008). This study was limited to 120 days to attempt to capture variation in AMF colonization across the growing season prior to flowering.

\section{Cloning Procedure}

Plants were vegetatively propagated to assess AMF response in an individual without having to account for variation in a maternal line, as would be needed if seedlings were used. Nine plants per population were needed for three replicates per population for each harvest $(60,90,120$ days). Three maternal lines were used, with either siblings or single individuals replicated across harvest. A minimum of eight and a maximum of 20 tillers from each chosen individual were separated, the shoot was cut to approximately five centimeters tall, the rhizome cleaned of all soil, and all roots were removed to eliminate prior colonization by arbuscular mycorrhizal fungi from the greenhouse. The remaining root bulb for each tiller was dipped in two rooting hormones, root tone containing fungicide (GardenTech, Palatine, IL) and root juice (BioBizz, San Jose, CA) free of fungicide, to stimulate root growth. Prior cultivation of tillers demonstrated maximal root regrowth with the use of both rooting hormones. Tillers were planted in sterilized potting media (Sunshine mix soil-less potting media, Sun-Gro Horticulture, Agawam, MA) using a double autoclaving procedure (two cycles of 60 minutes at $121^{\circ} \mathrm{C}$ with a 24 hour cooling period in between). 
After planting, tillers were watered heavily and covered with plastic domes to prevent desiccation and allowed to re-grow roots for 3 weeks. After re-rooting, four to twelve tillers per individual (depending on replication across harvests) with the largest amount of root growth were washed under tap water, weighed, and transplanted into 10x10x10 $\mathrm{cm}$ pots (Anderson Die and Manufacturing Co., Portland, OR), for a total of 324 plants ( 81 plants pre treatment, 109 plants per harvest).

\section{Inoculum}

Whole rhizosphere soil used for AMF inoculum was collected from ten individuals two weeks (August 22 and 24,2011) prior to transplanting tillers from six populations ( 60 plants total), using the same populations used in the experiment in Corvallis (C1 and C10, no B. sylvaticum could be located at C6) and Eugene (E4, E7, and E9). Samples were sieved through $1.5 \mathrm{~cm} \mathrm{X} 1.5 \mathrm{~cm}$ mesh to remove large debris and rocks, then mixed together in equal parts to limit the effects of nutrient variation between sites and to provide as diverse a community of B. sylvaticum associated AMF in Oregon, USA as possible. Half of the mixed soil was sterilized twice by autoclaving for 60 minutes at $121^{\circ} \mathrm{C}$ with 24 hours between cycles. Sand was also sterilized using the same procedure. Prior to transplanting tillers, pots were filled with $45 \%$ sterilized sand, $45 \%$ Sunshine Mix soil-less potting media (7080\% Canadian sphagnum peat moss, perlite, dolomitic limestone, gypsum, wetting agent; Sun-Gro Horticulture), and 10\% whole field soil or sterile field soil. Only $10 \%$ field soil was used to limit the nutrient differences cause by autoclaving. $500 \mathrm{~mL}$ of 
both inoculated and sterile potting media was sampled, dried, and analyzed for nutrient content by A\&L Western Laboratories INC. (Portland, OR) to confirm similar nutrient status between inoculated and sterile soils.

\section{Growth Conditions and Fertilizer Treatments}

The experiment was conducted in the Portland State University Research Greenhouse with the temperature maintained between $15.5^{\circ} \mathrm{C}$ and $26.7^{\circ} \mathrm{C}$, and 20 $\mathrm{Mw} / \mathrm{cm}^{2}$ to $40 \mathrm{Mw} / \mathrm{cm}^{2}$ supplemental light provided between $7 \mathrm{am}$ and $7 \mathrm{pm}$ with 1000W HID bulbs (Philips Co., NV, USA). Plants were arranged in a randomized design, grouping treatments to prevent AMF contamination by watering, and were rotated in both position and orientation every week within groups; groups were similarly rotated weekly. Fertilized treatments received $100 \mathrm{ml}$ of Dr. Earth concentrate fertilizer diluted as directed by the manufacturer (Dr. Earth Co., Winters, CA, USA) resulting in 3-3-3 percent NPK on days 1, 31, 60, and 91. Plant height and tiller number were recorded every week until the 60 day harvest and biweekly until the 120 day harvest. Plant size was calculated by multiplying tiller number and height, and was used as an estimate of fitness. Chlorophyll content (Minolta SPAD502 Leaf Chlorophyll meter) was measured starting on week 4 (to allow for necessary shoot growth required to make an accurate reading). 


\section{Harvest}

Final growth measurements were taken one day prior to destructive harvest. At harvest, plants were removed from each pot, shaken, rinsed in tap water to remove all remaining media, patted dry and weighed (total root wet mass) before being sampled for AMF colonization. Roots were sampled for AMF colonization by removing approximately equal weights (when enough roots were available) from three random and independent places in the root, placed in histocassettes and stored in tap water at $4^{\circ} \mathrm{C}$ until stained (VWR, West Chester, PA). Sampled roots were re-weighed (sampled root wet mass) and roots and shoots were dried at $60^{\circ} \mathrm{C}$ until constant mass was reached. Shoots and roots were then weighed, producing shoot dry mass and sampled root dry mass. Total dried root mass (root dry mass) was estimated by multiplying total root wet mass by sampled root dry mass, then

dividing by sampled root wet mass. Specific leaf area (the ratio of leaf area over dry mass) was measured for all plants to standardize chlorophyll meter readings. Potting media was bagged and stored at $4{ }^{\circ} \mathrm{C}$ until spore extractions could be performed. $100 \mathrm{~mL}$ of soil from each sample were combined for each treatment at each harvest, homogenized, dried, and $500 \mathrm{ml}$ was subsampled for nutrient testing (A\&L Western Laboratories INC., Portland, OR).

Assessment of Arbuscular Mycorrhizal Colonization

To quantify the level of AMF colonization of plants, roots were cleared with $10 \% \mathrm{KOH}$, followed by a 30 second soak in $5 \%$ bleach, neutralized in $2 \% \mathrm{HCl}$, and 
stained with $0.05 \%$ Trypan blue, as described by Phillips and Hayman (1970).

Stained roots were cut into approximately $1 \mathrm{~cm}$ segments and placed on microscope slides in rows in lactoglycerol. A minimum of $50 \mathrm{~cm}$ of root was assessed for percent colonization by arbuscular mycorrhizal hyphae, arbuscules, vesicles and the percent of roots containing any of the three structures (\%AMF) using the slide-intersect method (McGonigle, et al. 1990).

Quantification of Arbuscule Mycorrhizal Fungal Spore Density

Arbuscular mychorrhizal fungal fitness was estimated by quantifying spore production through spore densities for all plants at harvest. Spore density was measured by weighing approximately $50 \mathrm{~g}$ potting media from each pot, agitating potting media with dish soap and tap water in a warring blender, and rinsing mixture with a high pressure nozzle through 3 sieves of $515.62 \mu \mathrm{m}, 248.92 \mu \mathrm{m}$, and $38 \mu \mathrm{m}$ pore size, stacked largest to smallest, until all soap suds were eliminated. Remaining sediment from the $248.92 \mu \mathrm{m}$ and $38 \mu \mathrm{m}$ sieves was collected into $50 \mathrm{ml}$ conical vials, $20 \mathrm{ml}$ of $60 \%$ sucrose solution was added, and vials were centrifuged at $2700 \mathrm{rpm}$ for two minutes. Supernatant was emptied into the $38 \mu \mathrm{m}$ sieve and rinsed before being transferred to a petri dish. Spores were visualized at $45 \mathrm{X}$ magnification and whole spore counts were performed (VWR, West Chester, PA). Spore counts were divided by sampled potting media weight to obtain spore density (spores/g) estimates. Extraction of the $515.62 \mu \mathrm{m}$ sievate was performed for a 
subset of samples across regions and inoculated treatments to ensure spore absence at the large pore size.

\section{Statistical Analysis}

Prior to data analysis, experimental plants with no root growth at harvest were excluded, resulting in 226 samples analyzed. Plant growth responses to inoculation were analyzed by treatment and region. AMF colonization across all harvests was summed together to create total \%AMF colonization measures (total \%AMF, total \%arbuscule, total \%vesicle, total \%hyphae) to be used as covariates for analyses of spore density. Plant size, chlorophyll content, biomass, shoot dry mass, \%AMF, \%arbuscules, \%vesicles and \%hyphae were log transformed to normalize the data. All analyses were performed in SAS (version 9.2).

Differences in plant biomass and dry shoot mass between treatments and harvest dates were analyzed using a mixed-model ANCOVA, with harvest date, inoculation, and fertilization as fixed effects, and weight at day zero as a covariate. Differences in plant growth (plant size and chlorophyll content) responses to colonization by AMF under high and low nutrient treatments were analyzed for each harvest with an ANCOVA model, with fertilization and inoculation treatments held as fixed effects, and size at day zero and average specific leaf area (calculated as the average specific leaf area for each replicate across all 3 harvests) for chlorophyll content only were included as a covariates. 
To assess the effects of inoculation on arbuscular mycorrhizal colonization, a one-way ANOVA model was used, with inoculation as a fixed effect. Differences in total percent AMF colonization (total \%AMF) between fertilized plants and plants from different regions (Corvallis, Eugene, and Europe) were analyzed using a mixedmodel ANCOVA, where fertilization and region were fixed effects, and weight of plants at day zero and chlorophyll content of plants for the 90 day harvest were covariates. Differences in arbuscular mycorrhizal fungal structures (\%arbuscules, \%vesicles, and \%hyphae) were analyzed using a mixed-model ANCOVA, with fertilization and region as fixed effects and plant weight at day zero as a covariate.

Differences in spore density between treatments and regions at each harvest (90 and 120 days; there were no live spores found in the 60 day harvest) were analyzed separately using a mixed-model ANCOVA with inoculation, fertilization and region as fixed effects and \%arbuscules at each harvest respectively and weight of the plant at day zero included as covariates.

\section{Results}

Plant Growth

Fertilized and inoculated plants had the largest average biomass $(3.05 \pm 0.29$, mean \pm std. err. given throughout), while unfertilized inoculated plants had reduced average biomass $(1.18 \pm 0.08)$ compared to all sterile plants (fertilized $=2.26 \pm 0.26$, unfertilized $=2.46 \pm 0.20$; Table 2.2, Figure 2.2). Fertilization alone, harvest date and 
weight at day zero also had significant effects on plant biomass (Table 2.2). Shoot dry mass exhibited the same pattern. Fertilized and inoculated plants had the largest average shoot dry mass $(2.24 \pm 0.25)$ and unfertilized inoculated plants had the lowest average shoot dry mass $(0.60 \pm 0.05)$ compared to both sterile treatments (fertilized $=1.40 \pm 0.18$, unfertilized $=1.51 \pm 0.15$; Table 2.3; Figure 2.3). Harvest, fertilization, and weight at day zero also have significant effects on shoot dry mass.

Plants inoculated and fertilized had larger average size (60 day harvest, $362.09 \pm 59.54 ; 90$ day harvest, $584.80 \pm 77.15 ; 120$ day harvest, $15112.91 \pm 198.41$ ) than sterile fertilized plants (60 day harvest, 162.07 \pm 30.21 ; 90 day harvest, $310.41 \pm 48.95 ; 120$ day harvest, $888.21 \pm 177.79$ ), while plants inoculated and not fertilized had smaller average size (60 day harvest, 116.09 \pm 12.64 ; 90 day harvest, $138.55 \pm 17.61 ; 120$ day harvest, $164.62 \pm 20.77$ ) than sterile unfertilized plants for all harvests (60 day harvest, $342.87 \pm 36.96$; 90 day harvest, $380.85 \pm 57.02$; day 125 , 475.16 \pm 91.31 ; Table 2.4, Figure 2.4). Fertilization alone had a significant effect on plant size for the 90 and 120 day harvests, but not the 60 day harvest (Table 2.4). There was no significant effect of region on plant size (Table 2.4).

Fertilization had a significant effect on plant chlorophyll content at all three harvests (Table 2.5), with all fertilized plants containing significantly more chlorophyll than unfertilized plants. Additionally, inoculated plants had significantly less chlorophyll than sterile plants at all harvests (Table 2.5). The interaction between fertilization and inoculation was significant for the 60 and 120 day harvests (Table 2.5). Unfertilized inoculated plants contained less chlorophyll than 
all other treatments for all harvests, with sterile unfertilized plants only containing less chlorophyll than fertilized plants for the 120 day harvest (Figure 2.5).

Arbuscular Mycorrhizal Fungal Colonization and Spore Density

Inoculated plants had significantly higher percent of roots colonized by AMF at 120 days $\left(\% A M F ; F_{7 / 77}=3.41, p=0.004 ;\right.$ Figure 2.6 ). The effect of fertilization on \%AMF was significant for 120 days harvest (Table 2.6), with fertilized plants having higher \%AMF colonization $(9.31 \pm 1.82)$ than unfertilized plants $(0.69 \pm 0.48)$. Region had a significant effect on \%AMF colonization for the 120 day harvest (Table 2.6; Figure 2.7); Eugene had the highest level of AMF colonization (6.79 \pm 2.7$)$ while Corvallis and Europe had lower but similar levels to each other (Corvallis, 4.69 \pm 1.36 ; Europe, 4.83 \pm 1.8 ). Plants from Eugene had a greater difference in percent AMF colonization between fertilized and unfertilized plants compared to Corvallis and European plants (Figure 2.7). The effects of fertilization, region, and the interaction between fertilization and region on percent AMF colonization were not significant for plants at the 60 and 90 day harvests (Table 2.6).

The interaction between fertilization, inoculation and region was significant for arbuscular mycorrhizal spore density (AMF spores/g soil) for plants at the 90 day harvest (Table 2.7; Figure 2.8). Plants from Corvallis and Eugene had higher AMF spore densities in inoculated fertilized plants compared to all other treatments; additionally plants from Eugene had higher levels of AMF spore densities for both inoculated fertilized plants and sterile unfertilized plants 
compared to the other two treatments (Figure 2.8). Spore density at the 90 day harvest was also significantly affected by inoculation and fertilization $(\mathrm{p}=0.028$; Figure 2.9). Variation in AMF spore densities for plants at the 120 day harvest was not explained by fertilization, inoculation or region (Table 2.7).

\section{Soil Nutrient Content}

Despite adding only $10 \%$ live or sterilized field soil to the sand and potting media mixture, inoculated potting media contained higher amounts of nitrogen, phosphorus and potassium than sterile media (inoculated media: $65 \mathrm{ppm} \mathrm{NO}_{3}{ }^{-}, 78$ ppm $\mathrm{P}_{\mathrm{i}}$ fractions $\left(\mathrm{P}_{\mathrm{i}}\right), 45 \mathrm{ppm} \mathrm{NaHCO}_{3}$ - extractable $\mathrm{P}$ using the Olsen method ( $\left.\mathrm{NaHCO}_{3}-\mathrm{P}\right), 217$ ppm K; sterile media: 41 ppm NO${ }_{3}^{-}, 37$ ppm $\mathrm{P}_{\mathrm{i}}, 25$ ppm NaHCO${ }_{3}-\mathrm{P}$, $133 \mathrm{ppm} \mathrm{K}$ ). At the 90 day harvest, fertilized media on average contained 6.1 times more nitrogen, $2.3\left(\mathrm{P}_{\mathrm{i}}\right)$ and $1.4\left(\mathrm{NaHCO}_{3}-\mathrm{P}\right)$ times more phosphorus, and 2.5 times more potassium than unfertilized media. Within fertilized potting medias, inoculated media contained higher quantities of all three nutrients compared to sterile soils (inoculated: $139 \mathrm{ppm} \mathrm{NO}_{3}, 50 \mathrm{ppm} \mathrm{P}, 22 \mathrm{ppm} \mathrm{NaHCO}_{3}-\mathrm{P}, 212 \mathrm{~K}$; sterile 118 ppm $\mathrm{NO}_{3}{ }^{-}, 41$ ppm $\mathrm{P}_{\mathrm{i}}, 19$ ppm $\left.\mathrm{NaHCO}_{3}-\mathrm{P}, 206 \mathrm{~K}\right)$. Conversely, inoculated unfertilized media contained slightly lower amounts of nitrogen and phosphorus than sterile unfertilized media (inoculated: $18 \mathrm{ppm} \mathrm{NO}_{3}{ }^{-}, 18 \mathrm{ppm} \mathrm{P} \mathrm{P}_{\mathrm{i}}, 14 \mathrm{ppm}$

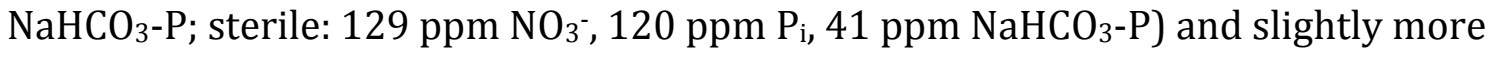
potassium (inoculated: $97 \mathrm{ppm} \mathrm{K}$; sterile: $89 \mathrm{ppm} \mathrm{K}$ ) at the 90 day harvest. At the 120 day harvest fertilized media on average contained 5.3 times more nitrogen, 4.1 
$\left(\mathrm{P}_{\mathrm{i}}\right)$ and $3\left(\mathrm{NaHCO}_{3}-\mathrm{P}\right)$ times more phosphorus, and 1.8 times more potassium than unfertilized soils. For all fertilized media, inoculated media contained lower amounts of nitrogen, phosphorous, and potassium than sterile media (inoculated: 82 ppm $\mathrm{NO}_{3}, 75$ ppm $\mathrm{P}_{\mathrm{i}}, 34$ ppm NaHCO $3_{3}-\mathrm{P}, 173 \mathrm{~K}$; sterile: 129 ppm $\mathrm{NO}_{3}{ }^{-}, 120$ ppm $\mathrm{P}_{\mathrm{i}}, 41 \mathrm{ppm} \mathrm{NaHCO}_{3}-\mathrm{P}, 205 \mathrm{~K}$ ), while inoculated and sterile unfertilized media contained similar amounts of all nutrients (inoculated: 17 ppm NO $3^{-}, 24$ ppm $\mathrm{P}_{\mathrm{i}}, 13$ ppm $\mathrm{NaHCO}_{3}-\mathrm{P}, 106 \mathrm{~K}$; sterile: 23 ppm $\mathrm{NO}_{3}{ }^{-}, 23$ ppm $\mathrm{P}_{\mathrm{i}}, 12$ ppm $\mathrm{NaHCO}_{3}-\mathrm{P}, 99 \mathrm{~K}$ ).

\section{Discussion}

I found no evidence of reduced mycorrhizal dependence in the invasive populations of B. sylvaticum. There were no significant differences in any of the plant growth measures between the invasive and native regions. There were regional effects for total percent AMF colonization for the 120 day harvest and spore production at the 90 day harvest. Increased percent roots colonized by AMF and increased spore production in Eugene compared to Corvallis and Europe suggests that AMF incur more fitness gains in high nutrient treatments when interacting with plants from Eugene than plants from either Corvallis or Europe. Since there are known genetic differences between Eugene and Corvallis and source European populations, it is possible that there is a genetic basis for the increase in carbon allocation to AMF resulting in increases AMF fitness. The differences in spore densities across all treatments was driven by high spore densities found in sterile unfertilized plants from Europe. 
Interestingly, I found increased plant and fungal fitness in the inoculated fertilized treatment compared to the inoculated unfertilized treatment. Studies have shown increased fitness gains by plants and fungi in high nutrient treatments (Treseder and Allen 2002; Nijjer, et al. 2008; Panwar, et al. 2011). Treseder and Allen (2002) found increased AMF biomass in nitrogen and phosphorus deficient soils when fertilized with nitrogen and phosphorus, though plant growth was not measured. Nijjer et al. (2008) demonstrated increased growth of plants in fertilized soils with AMF colonization that was greater than the increased growth of plants either fertilized or colonized by AMF combined. Neither study measured both AMF fitness and plant fitness to show an improved mutualistic interaction between AMF and plants in high nutrient treatments, as has been demonstrated in this study. Additionally, research that has demonstrated decreased plant growth in high nutrient treatments with AMF colonization have not measured fungal fitness to confirm parasitism, which requires a fitness increase for one partner with a fitness decrease for the other (Johnson 1993; Kahiluoto, et al. 2001; Daleo, et al. 2008). While a mutualistic relationship between AMF and B. sylvaticum was found in the high nutrient treatment, an antagonistic relationship was found in the low nutrient treatment. B. sylvaticum had decreased biomass, size, and chlorophyll content with inoculation in the unfertilized treatment compared to all other treatments. Additionally, there were reduced, almost negligible AMF spore densities in the unfertilized treatment. The reduction in both plant and AMF fitness suggests that competition rather than parasitism is occurring at low nutrient levels. The 
assumption that AMF always incur a fitness gain due to colonization has been used as the rational for the mutualism-parasitism continuum in plant-AMF interactions. However, plants recruit AMF colonization (Sylvia and Neal 1990; Schwab, et al. 1991) and allocate sugar to AMF based on nutrients acquired (Pearson and Jakobsen 1993; Correa, et al. 2014). If sugar allocation by plants is limited such that AMF growth is increased but AMF cannot reproduce, plants would be using AMF as a root extension without benefiting AMF fitness. AMF spore production compared to hyphal length is a greater measure of AMF fitness due to increased survival of spores across time (Douds 1994). Therefore, reduced spore production coupled with reduced plant growth demonstrates reduced fitness for both plants and AMF classified as competition.

The limiting resource in this competitive interaction is most likely nitrogen. Competition between soil microorganisms and plants for nitrogen has previously been shown (Hawkes 2003), and there is evidence that AMF are nitrogen limited in low nutrient soils (Treseder and Allen 2002; Grman and Robinson 2013). The significantly reduced chlorophyll content of B. sylvaticum leaves were recorded beginning at day 44 and remained reduced throughout the remainder of the experiment in the unfertilized, inoculated treatment. Nitrogen content in unfertilized inoculated soils was the most reduced of all other nutrients compared to fertilized inoculated soils, with 17 and $18 \mathrm{ppm} \mathrm{NO}_{3}{ }^{-}$after 90 and 120 days respectively. Field concentrations of $\mathrm{NO}_{3}{ }^{-}$have been reported as $10 \mathrm{ppm}$ (Marchini and Cruzan). The similarity in nitrogen content between the unfertilized inoculated 
soils in this study and field conditions suggests that the AMF symbiosis with $B$. sylvaticum in the invasive range is most likely antagonistic if other species interactions were absent.

There is some evidence of temporal variation in the AMF symbiosis with $B$. sylvaticum. The differences in plant size due to treatments increased from the 60 day to the 120 day harvest. Chlorophyll content in unfertilized inoculated plants was significantly lower at day 44 than all other treatments, but plants for the other three treatments had similar chlorophyll content measures until day 78, with both fertilized treatments remaining similar until the final harvest date. The delay in the separation of treatments is most likely due to the time it takes AMF to colonize and grow before nutrients are supplied to the plant. Perhaps more interestingly, percent of roots colonized by AMF were significantly different between fertilized and unfertilized treatments overall, but only at the 120 day harvests when the 90 and 120 day harvests were analyzed independently. Similarly, spore densities were significantly different across all treatments overall and at the 90 day harvest but not the 120 day harvest when each harvest was analyzed separately. Research has shown increased AMF colonization when spore production is low and increased spore production when colonization is low (Panwar, et al. 2011). Douds et al. (1998) demonstrated differences among species of AMF in sporulation timing. Here, AMF colonization of plants harvested at 60 days was driven by chlorophyll content, indicating that AMF colonization was mediated by carbon allocation. Studies have shown variation in sporulation timing among AMF species (Sturmer and Siqueira 
2011; Velazquez and Cabello 2011). It is likely that the species of AMF that colonized B. sylvaticum in this study sporulate early, resulting in significant effects of treatments at the 90 day harvest rather than the 120 day harvest on spore densities.

The competitive outcome between AMF and B. sylvaticum demonstrated in this study is expected to be more complex under field conditions, as AMF form common mycelial networks between competing plants species (Simard and Durall 2004). AMF have been shown to impact competitive outcomes between plants (Goodwin 1992), and this has been demonstrated in B. sylvaticum (Workman and Cruzan, in preparation; , in review). Both interspecific and intraspecific competition of $B$. sylvaticum was mediated by AMF colonization; however, AMF colonization reduced growth of both species overall (Workman and Cruzan, in review). Additionally, $B$. sylvaticum had improved growth in soils from uninvaded ranges compared to invaded ranges. Considering results from both the study presented here and Workman's findings, it is likely that changes in AMF communities are occurring in invaded soils, and the altered AMF community is more able to take advantage of $B$. sylvaticum. Despite the lack of evidence for reduced mycorrhizal dependence in $B$. sylvaticum, the reduced and negative mycorrhizal interactions demonstrated in multiple studies of B. sylvaticum with invaded range AMF provide evidence of a selective pressure for adaptation for invasion in B. sylvaticum. Additionally, the reduced AMF colonization and spore production in Corvallis versus Eugene populations, which have different genotype compositions based on microsatilite work (Rosenthal, et al. 2008) suggests a possible genetic basis for the difference in 
AMF interactions, which is necessary for evolution to occur. The continued study of the interactions between invasive species and AMF that incorporate additional biotic and abiotic variables is necessary for developing a greater understanding of the role of one of the most pervasive and widespread mutualisms in plant invasions. 


\section{Tables}

Table 1.1. Population code, location, and global positioning system (GPS) coordinates (latitude and longitude in degrees, minutes, and seconds (DMS)) for 3 populations in Corvallis (C2, C3 and C5) and Eugene (E4, E6 and E9).

\begin{tabular}{llll} 
Code & Location & Latitude & Longitude \\
\hline C2 & Corvallis & $44^{\circ} 37^{\prime} 52^{\prime \prime}$ & $-123^{\circ} 18^{\prime} 16^{\prime \prime}$ \\
C3 & Corvallis & $44^{\circ} 42^{\prime} 37^{\prime \prime}$ & $-123^{\circ} 18^{\prime} 58^{\prime \prime}$ \\
C5 & Corvallis & $44^{\circ} 38^{\prime} 35^{\prime \prime}$ & $-123^{\circ} 20^{\prime} 11^{\prime \prime}$ \\
E4 & Eugene & $44^{\circ} 0^{\prime} 48^{\prime \prime}$ & $-122^{\circ} 52^{\prime} 30^{\prime \prime}$ \\
E6* & Eugene & $43^{\circ} 59^{\prime} 47^{\prime \prime}$ & $-122^{\circ} 47^{\prime} 57^{\prime \prime}$ \\
E9 & Eugene & $43^{\circ} 58^{\prime} 26^{\prime \prime}$ & $-122^{\circ} 50^{\prime} 33^{\prime \prime}$ \\
\hline
\end{tabular}

* Previously published as E6n (Rosenthal et al. 2008) 
Table 2.1. Population code, location, and global positioning system (GPS) coordinates (latitude and longitude) for 3 populations in the Corvallis region(C1, C6 and C10), Eugene region (E4, E7 and E9), and in Europe (ESH, IC2 and GIP).

\begin{tabular}{llll}
\hline Code & Location & Latitude & Longitude \\
\hline C1* & Corvallis & $44^{\circ} 39^{\prime} 35^{\prime \prime}$ & $-123^{\circ} 14^{\prime} 19^{\prime \prime}$ \\
C6 & Hwy 22/Corvallis & $44^{\circ} 45^{\prime} 19^{\prime \prime}$ & $-122^{\circ} 23^{\prime} 18^{\prime \prime}$ \\
C10 & Corvallis & $44^{\circ} 23^{\prime} 29^{\prime \prime}$ & $-123^{\circ} 21^{\prime} 56^{\prime \prime}$ \\
E4 & Eugene & $44^{\circ} 0^{\prime} 48^{\prime \prime}$ & $-122^{\circ} 52^{\prime} 30^{\prime \prime}$ \\
E7 & Eugene & $43^{\circ} 58^{\prime} 29^{\prime \prime}$ & $-122^{\circ} 38^{\prime} 47^{\prime \prime}$ \\
E9 & Eugene & $43^{\circ} 58^{\prime} 26^{\prime \prime}$ & $-122^{\circ} 47^{\prime} 57^{\prime \prime}$ \\
ESH & England, Shropshire & $52^{\circ} 37^{\prime} 32^{\prime \prime}$ & $-3^{\circ} 44^{\prime} 14^{\prime \prime}$ \\
IC2** & Italy, Calabria 2 & $39^{\circ} 32^{\prime} 18^{\prime \prime}$ & $16^{\circ} 12^{\prime} 31^{\prime \prime}$ \\
GIP & Greece, Ioannina 2 & $29^{\circ} 40^{\prime} 12^{\prime \prime}$ & $20^{\circ} 50^{\prime} 24^{\prime \prime}$ \\
\hline
\end{tabular}

* Previously published as C1n (Rosenthal et al. 2008)

** Previously published as ICB (Rosenthal et al. 2008) 
Table 2.2. ANCOVA table of degrees of freedom (DF), means squared (means ${ }^{2}$ ), f statistic (F), and probability (P) for the effect of harvest date (harvest), region, fertilization, region*fertilization, inoculation, region*inoculation, fertilization*inoculation, region*fertilization*inoculation, and initial plant weight (day 0) on final dry mass (biomass).

\begin{tabular}{|l|cccc|}
\hline Source & DF & Means $^{2}$ & $\mathrm{~F}$ & $\mathrm{P}$ \\
\hline harvest & 2 & 0.334 & 18.72 & $<.0001$ \\
region & 2 & 0.002 & 0.11 & 0.8979 \\
fertilization & 1 & 0.247 & 13.84 & $\mathbf{0 . 0 0 0 3}$ \\
region*fertilization & 2 & 0.007 & 0.39 & 0.6779 \\
inoculation & 1 & 0.051 & 2.86 & 0.0923 \\
region*inoculation & 2 & 0.004 & 0.22 & 0.8007 \\
fertilization*inoculation & 1 & 0.386 & 21.68 & $<.0001$ \\
region*fertilization*inoculation & 2 & 0.002 & 0.12 & 0.8854 \\
weight day 0 & 1 & 0.136 & 7.61 & $\mathbf{0 . 0 0 6 3}$ \\
\hline
\end{tabular}

* Values in bold are significant 
Table 2.3. ANCOVA table of degrees of freedom (DF), means squared (means ${ }^{2}$ ), f statistic (F), and probability (P) for the effect of harvest date (harvest), region, fertilization, region*fertilization, inoculation, region*inoculation, fertilization*inoculation, region*fertilization*inoculation, and initial plant weight (day 0) on final shoot dry mass.

\begin{tabular}{|l|cccc|}
\hline Source & DF & Means $^{2}$ & $\mathrm{~F}$ & $\mathrm{P}$ \\
\hline harvest & 2 & 0.21795655 & 13.56 & $<.0001$ \\
region & 2 & 0.00327612 & 0.2 & 0.8157 \\
fertilization & 1 & 0.34257391 & 21.32 & $<.0001$ \\
region*fertilization & 2 & 0.01069697 & 0.67 & 0.515 \\
inoculation & 1 & 0.01432378 & 0.89 & 0.3462 \\
region*inoculation & 2 & 0.01167898 & 0.73 & 0.4847 \\
fert*inoculation & 1 & 0.39679596 & 24.69 & $<.0001$ \\
region*fertilization*inoculation & 2 & 0.000902 & 0.06 & 0.9454 \\
weight day 0 & 1 & 0.14736338 & 9.17 & $\mathbf{0 . 0 0 2 8}$ \\
\hline
\end{tabular}

* Values in bold are significant 


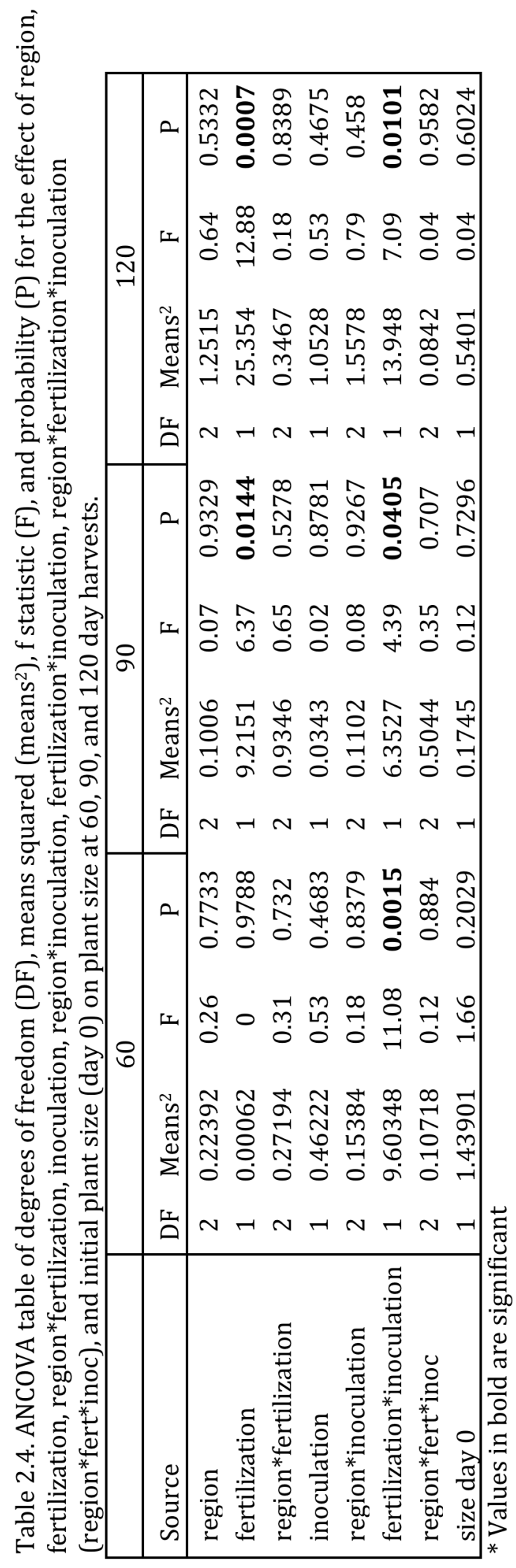




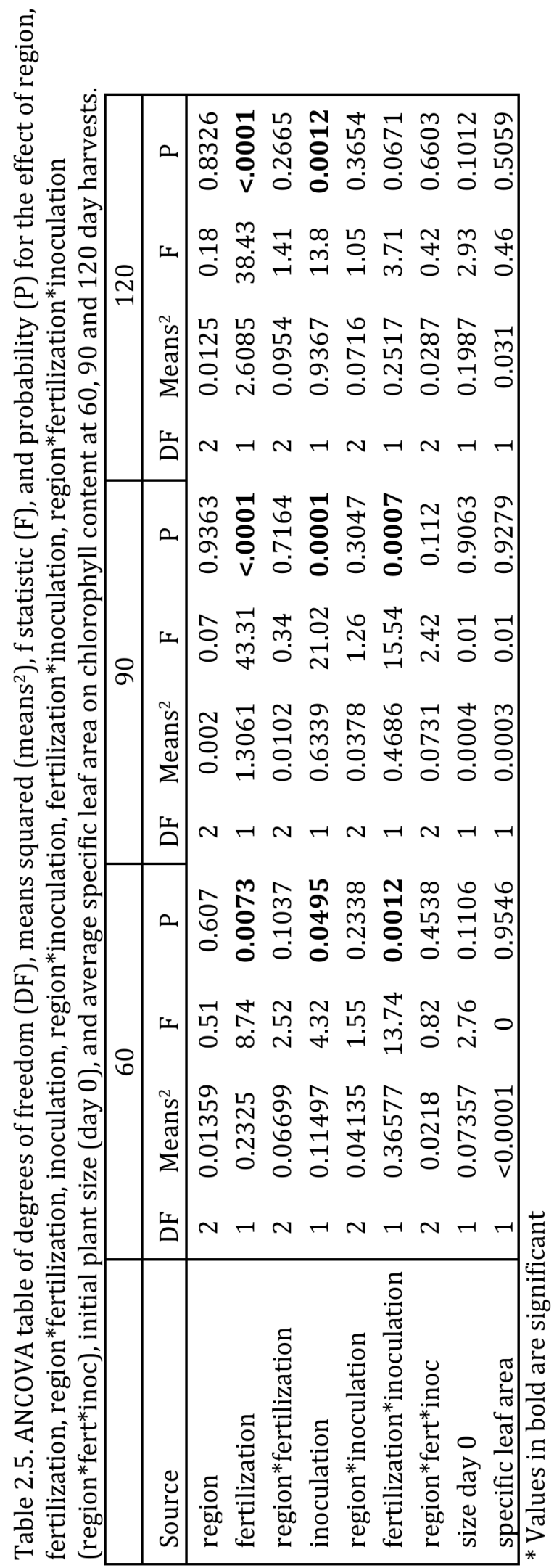




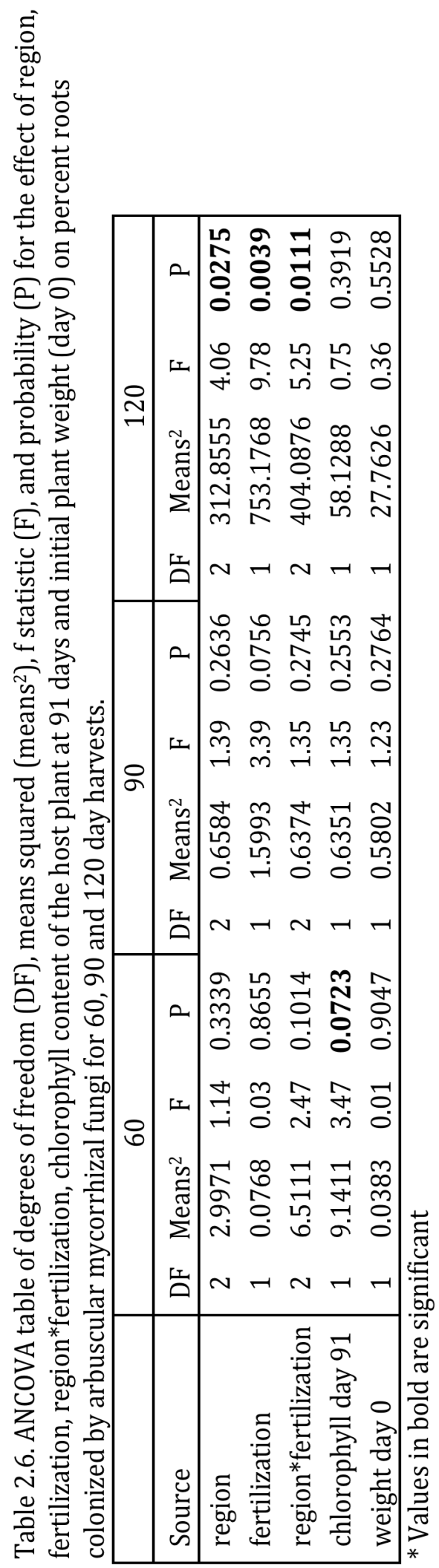




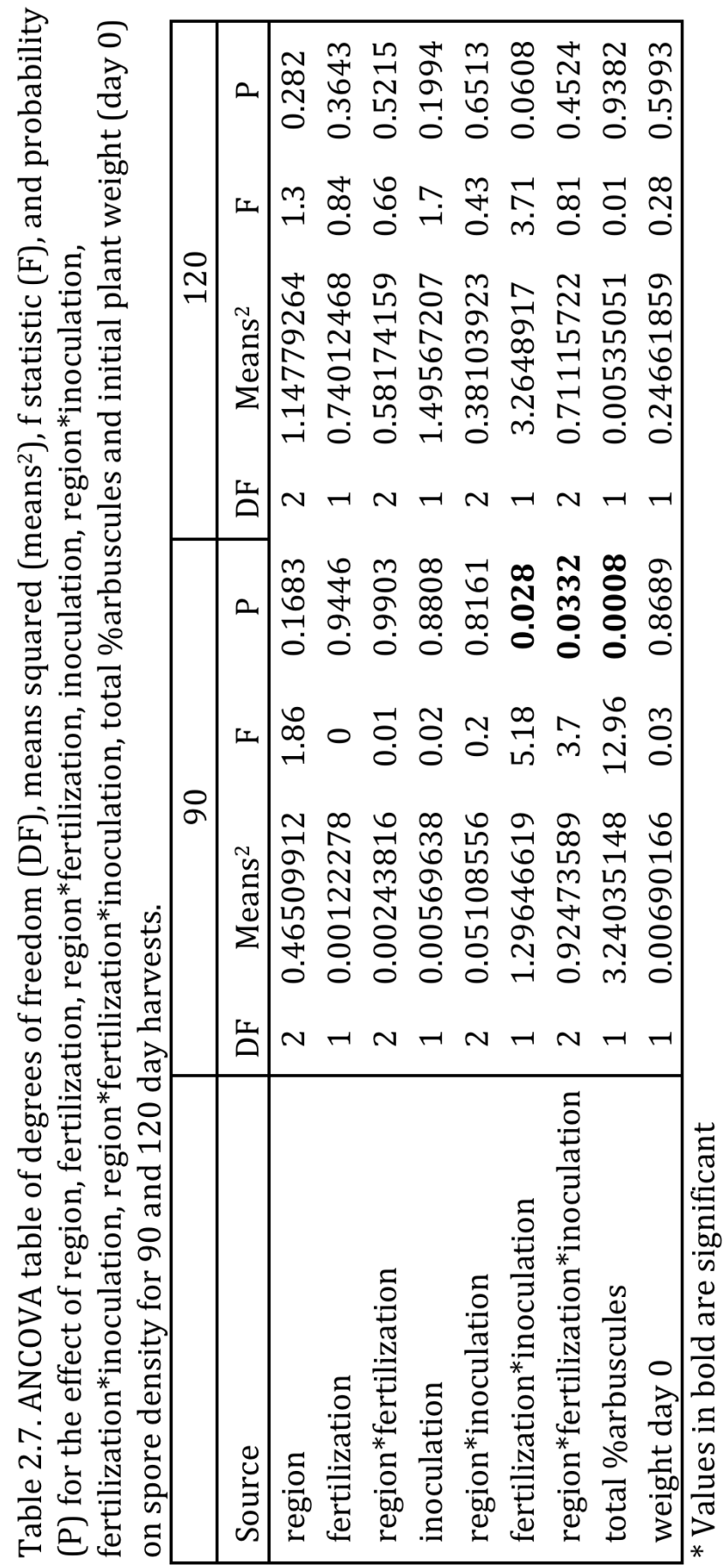




\section{Figures}

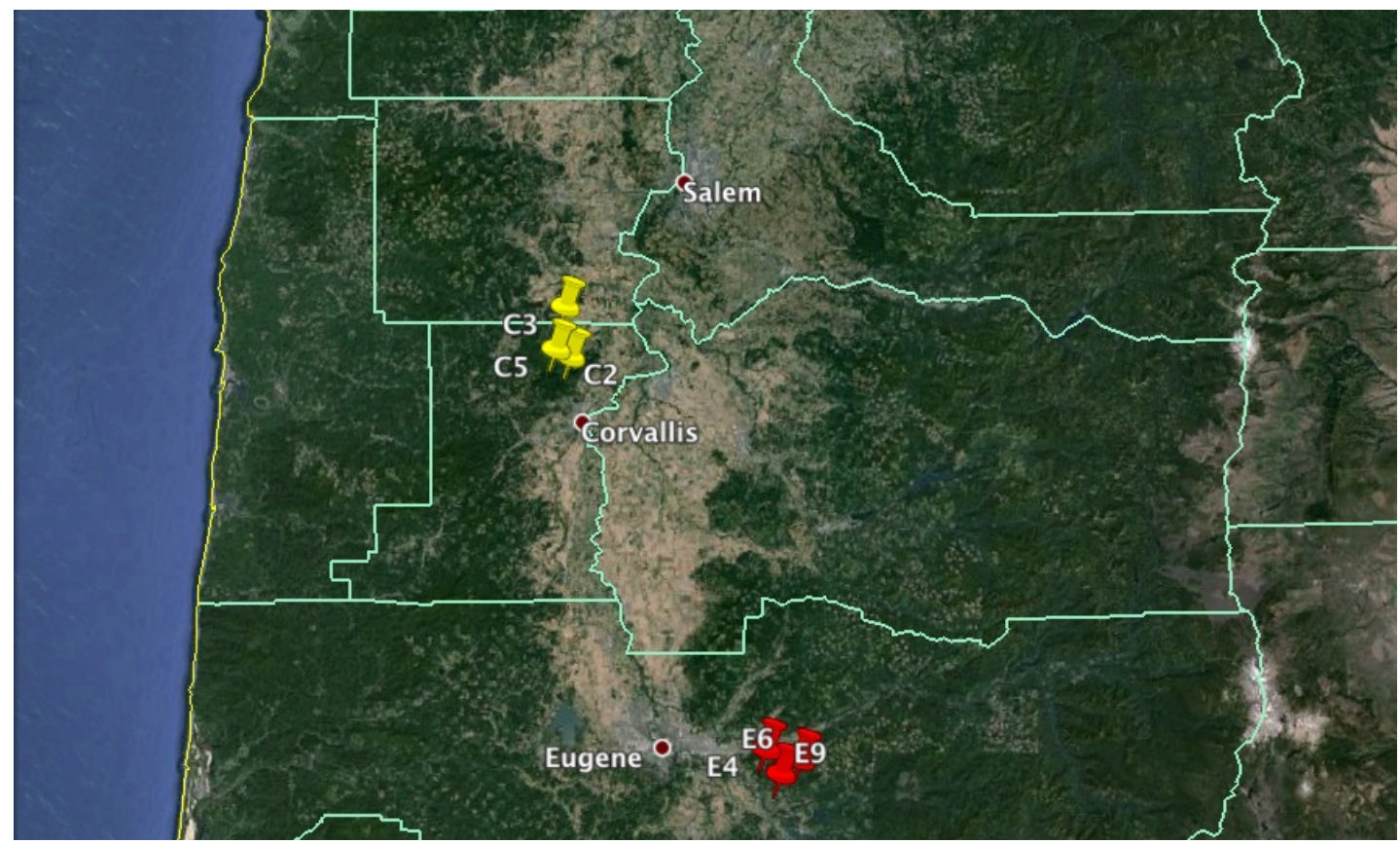

Figure 1.1. Population locations for sampled B. sylvaticum in Corvallis (C2, C3, and C5; shown in yellow) and Eugene (E4, E6, and E9; shown in red). 


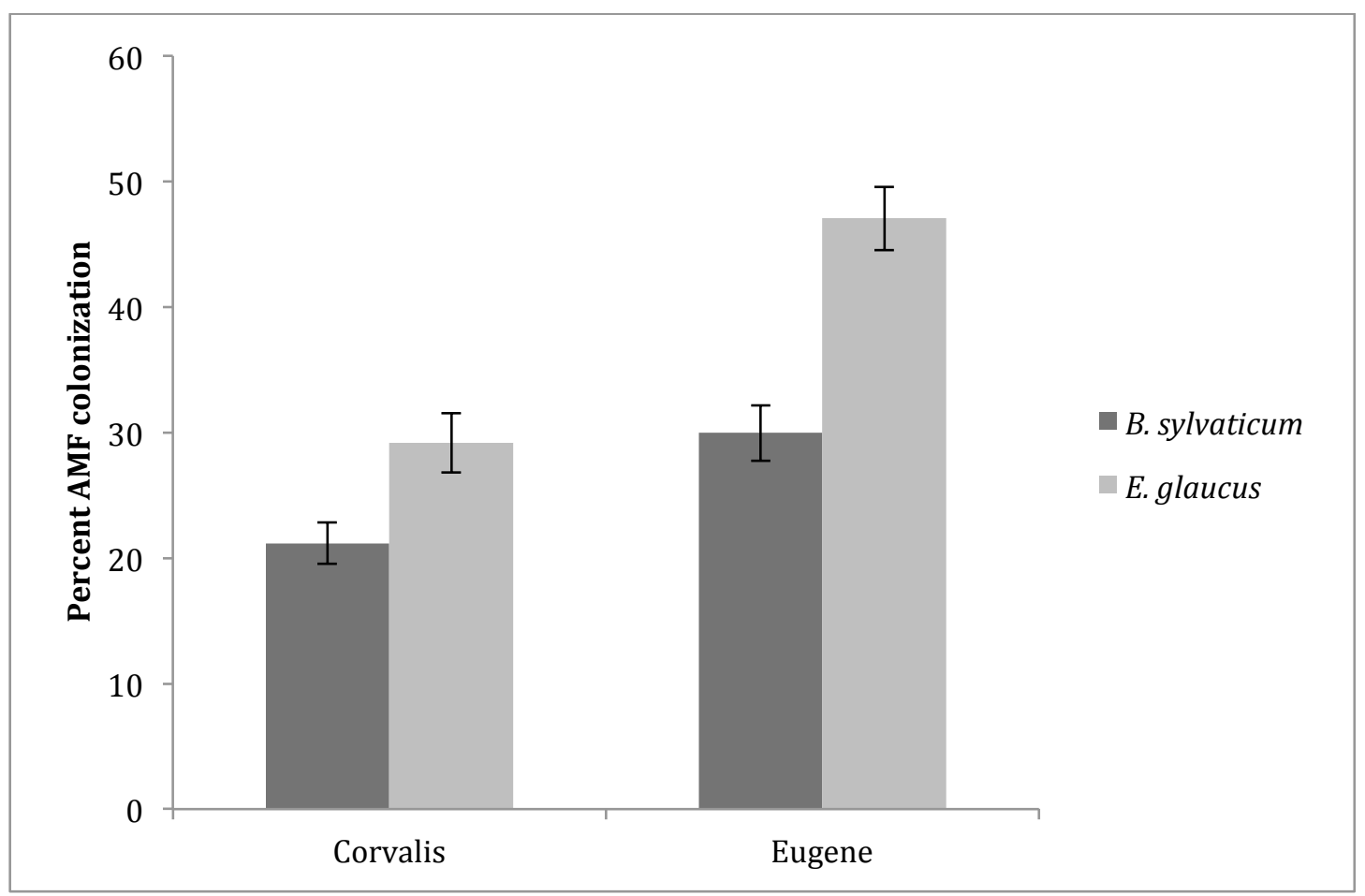

Figure 1.2. Percent AMF colonization of plant roots for B. sylvaticum and E. glaucus collected from Corvallis and Eugene. Error bars represent standard error. 


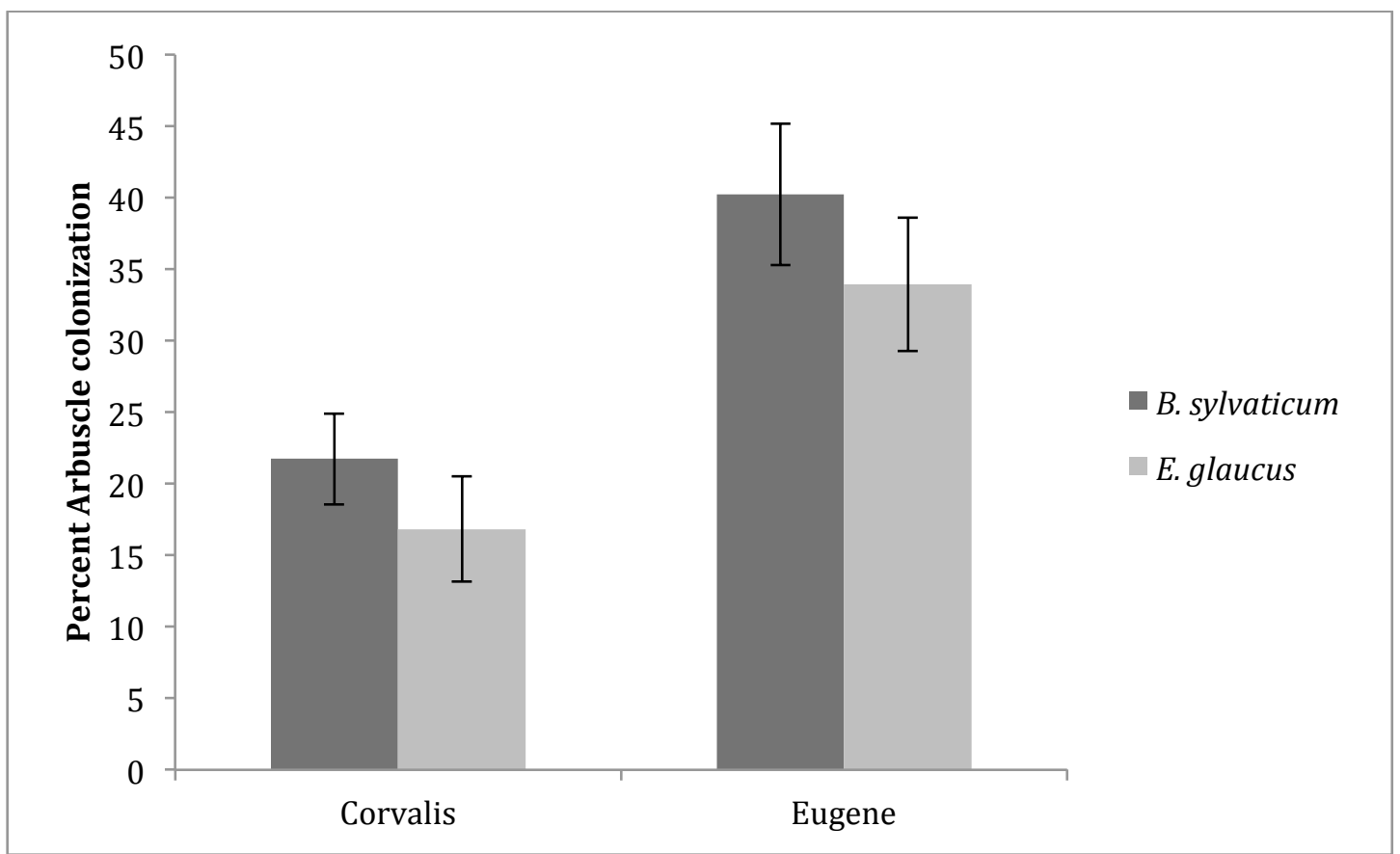

Figure 1.3. Percent of assayed roots containing arbuscules for B. sylvaticum and $E$. glaucus plants collected from Corvallis and Eugene. Error bars represent standard error. 


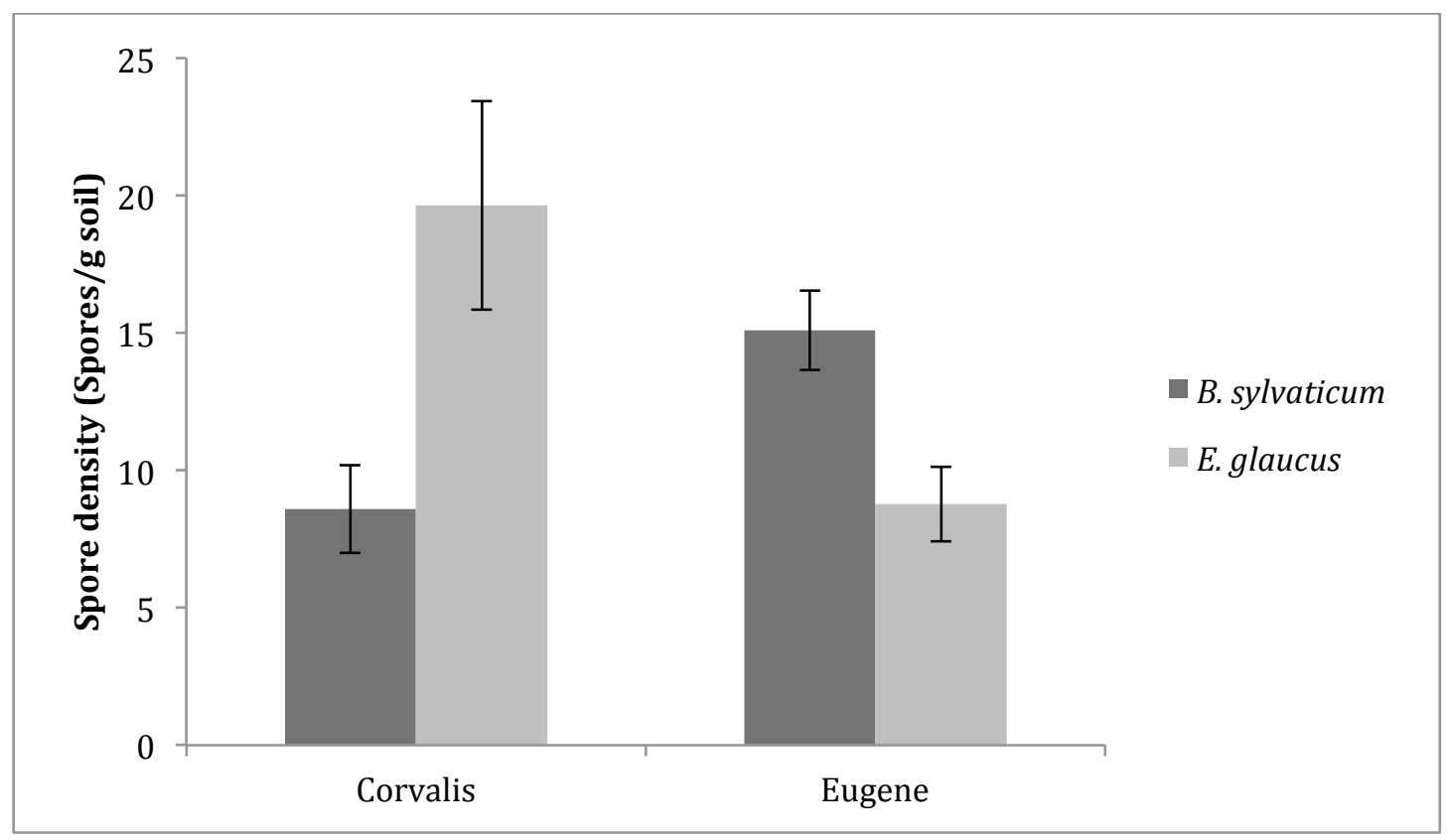

Figure 1.4. Spore density (spores/g soil) of the rhizosphere of B. sylvaticum and $E$. glaucus plants from Corvallis and Eugene. Error bars represent standard error. 


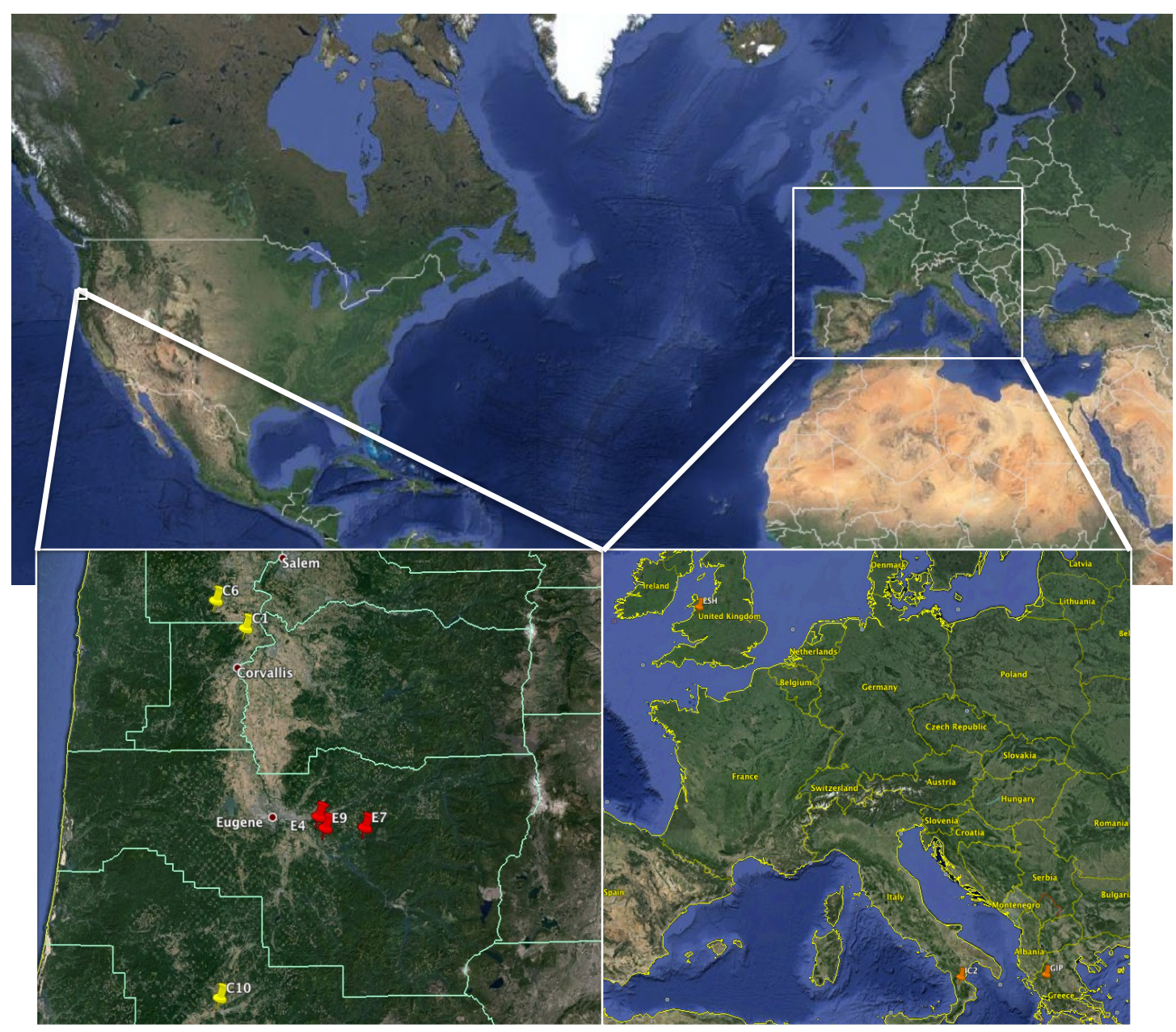

Figure 2.1. Population locations of B. sylvaticum samples from Corvallis (C1, C6, and C10; on the left, shown in yellow), Eugene (E4, E7, and E9; on the left, shown in red) and Europe (ESH, IC2, and GIP; on the right, shown in orange). 


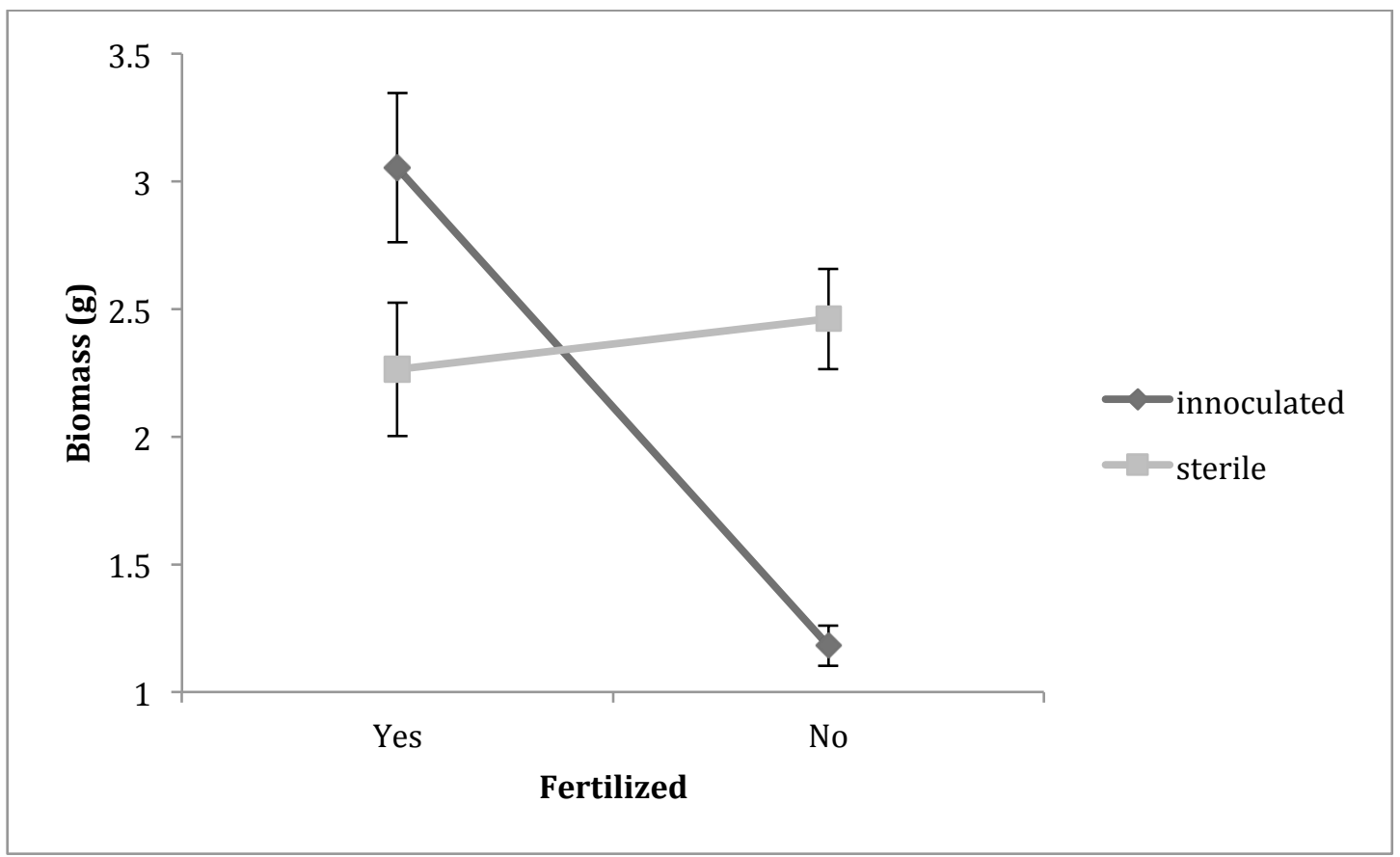

Figure 2.2. Final dry mass of fertilized and unfertilized inoculated and sterile plants for all harvests. Error bars represent standard error. 


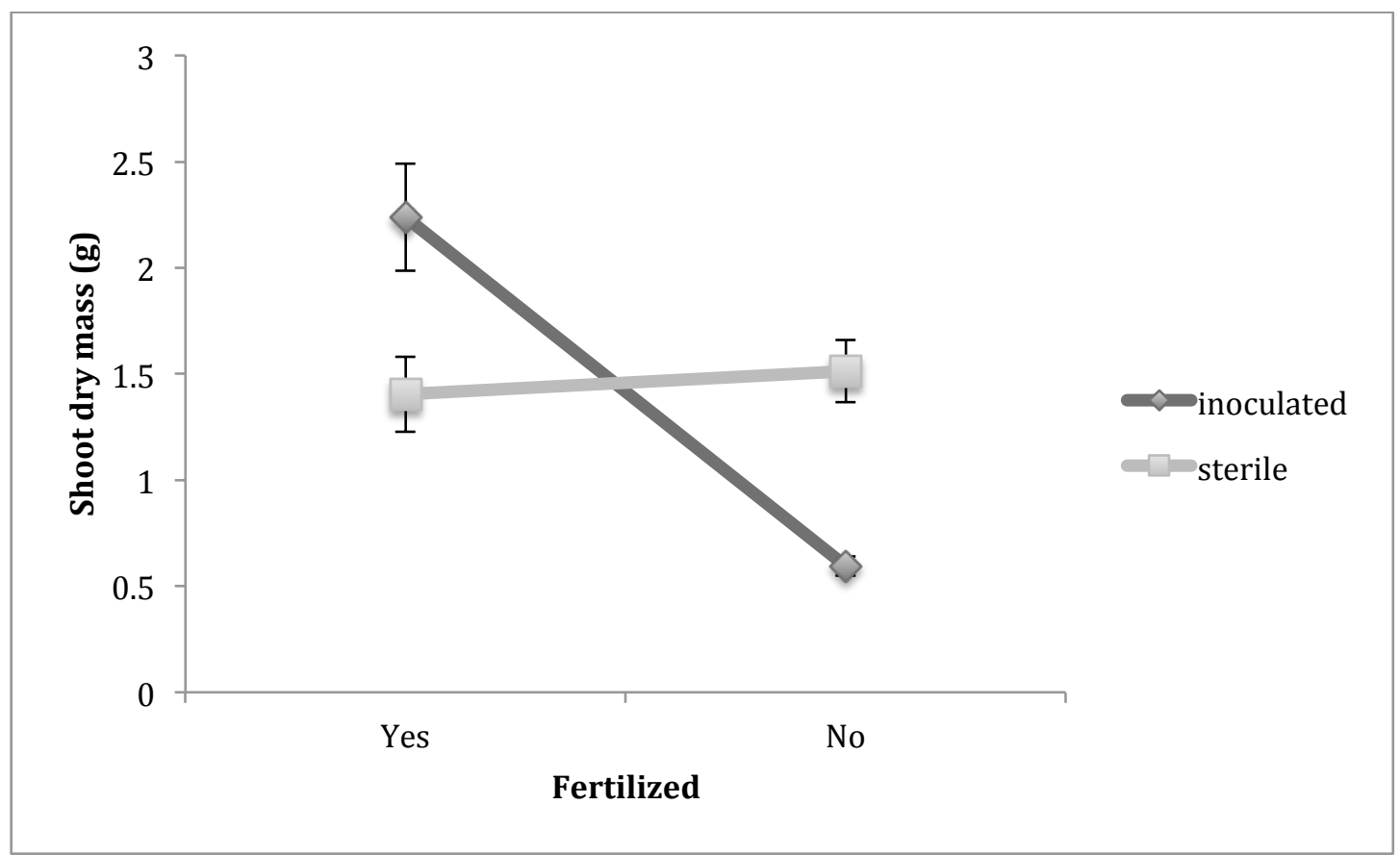

Figure 2.3. Final shoot dry mass of fertilized and unfertilized inoculated and sterile plants for all harvests. Error bars represent standard error. 


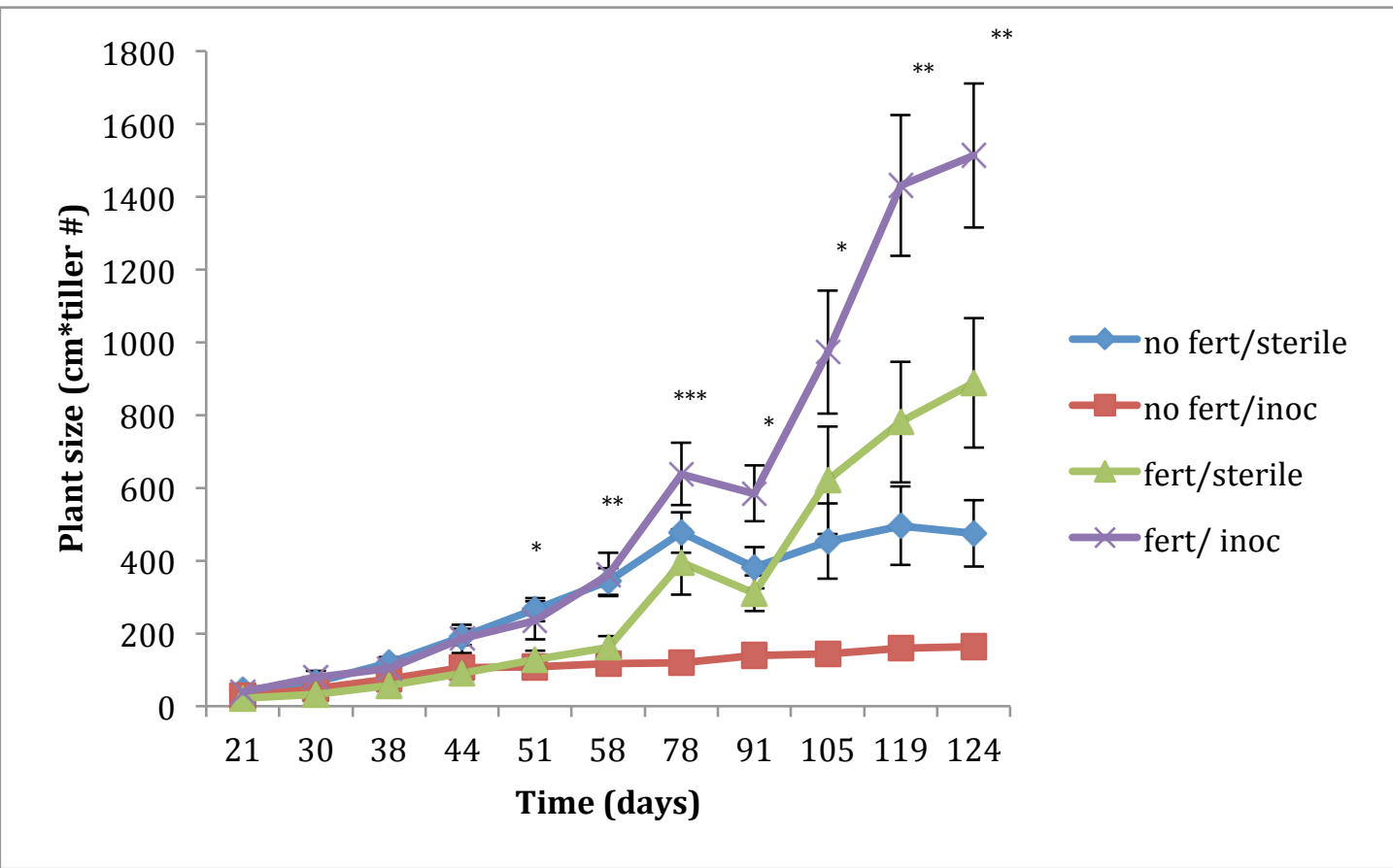

Figure 2.4. Plant size (tiller number * plant height $(\mathrm{cm})$ over 124 days of all treatments averaged across all harvests. Error bars represent standard error. * indicates $\mathrm{p} \leq 0.05,{ }^{* *}$ indicates $\mathrm{p} \leq 0.01$, and ${ }^{* * *}$ indicates $\mathrm{p} \leq 0.001$ for the interaction between inoculation and fertilization. 


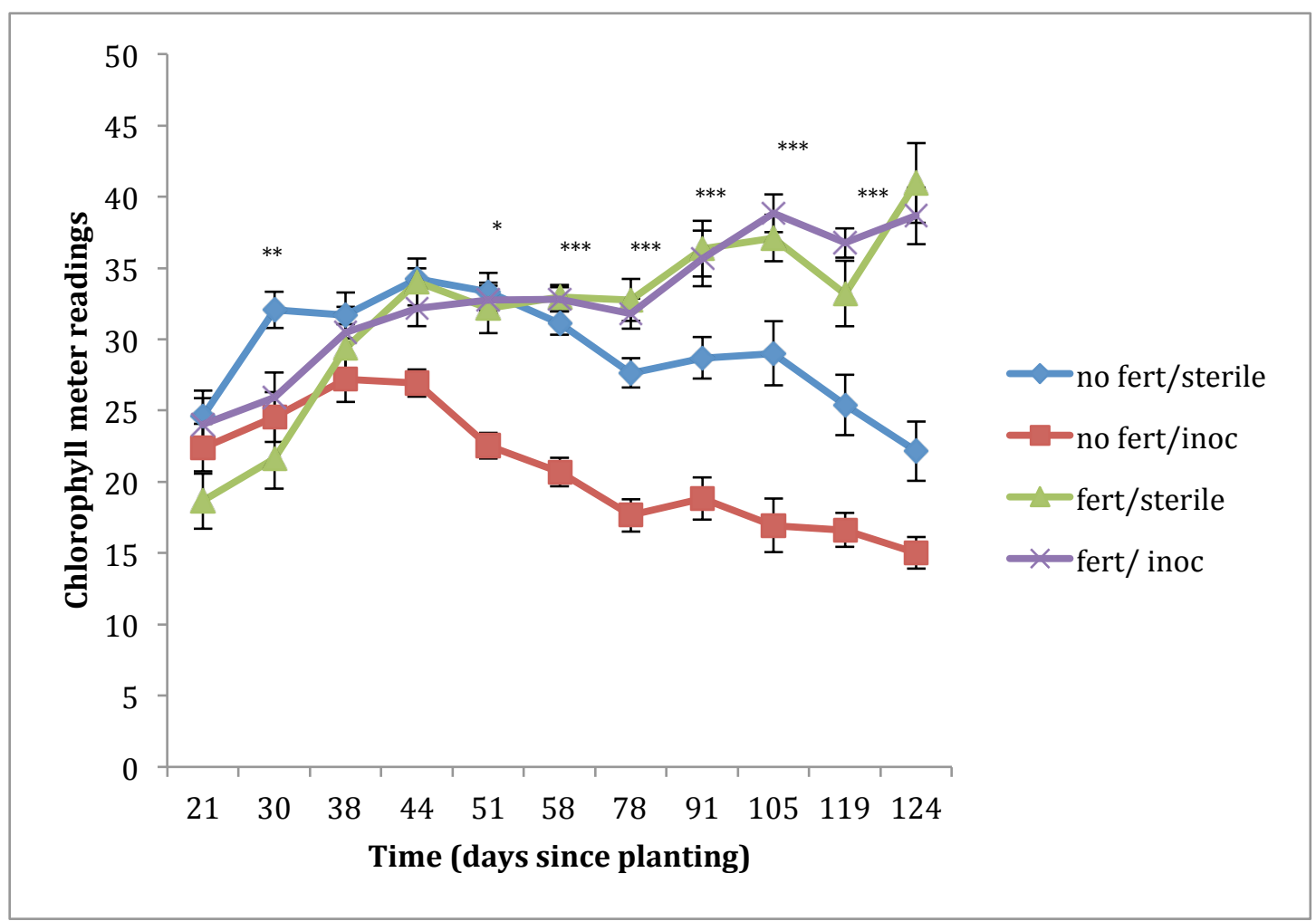

Figure 2.5. Chlorophyll meter readings over 124 days for all treatments averaged over all harvests. Error bars represent standard error. * indicates $\mathrm{p} \leq 0.05$, ** indicates $\mathrm{p} \leq 0.01$, and ${ }^{* * *}$ indicates $\mathrm{p} \leq 0.001$ for the interaction between inoculation and fertilization. 


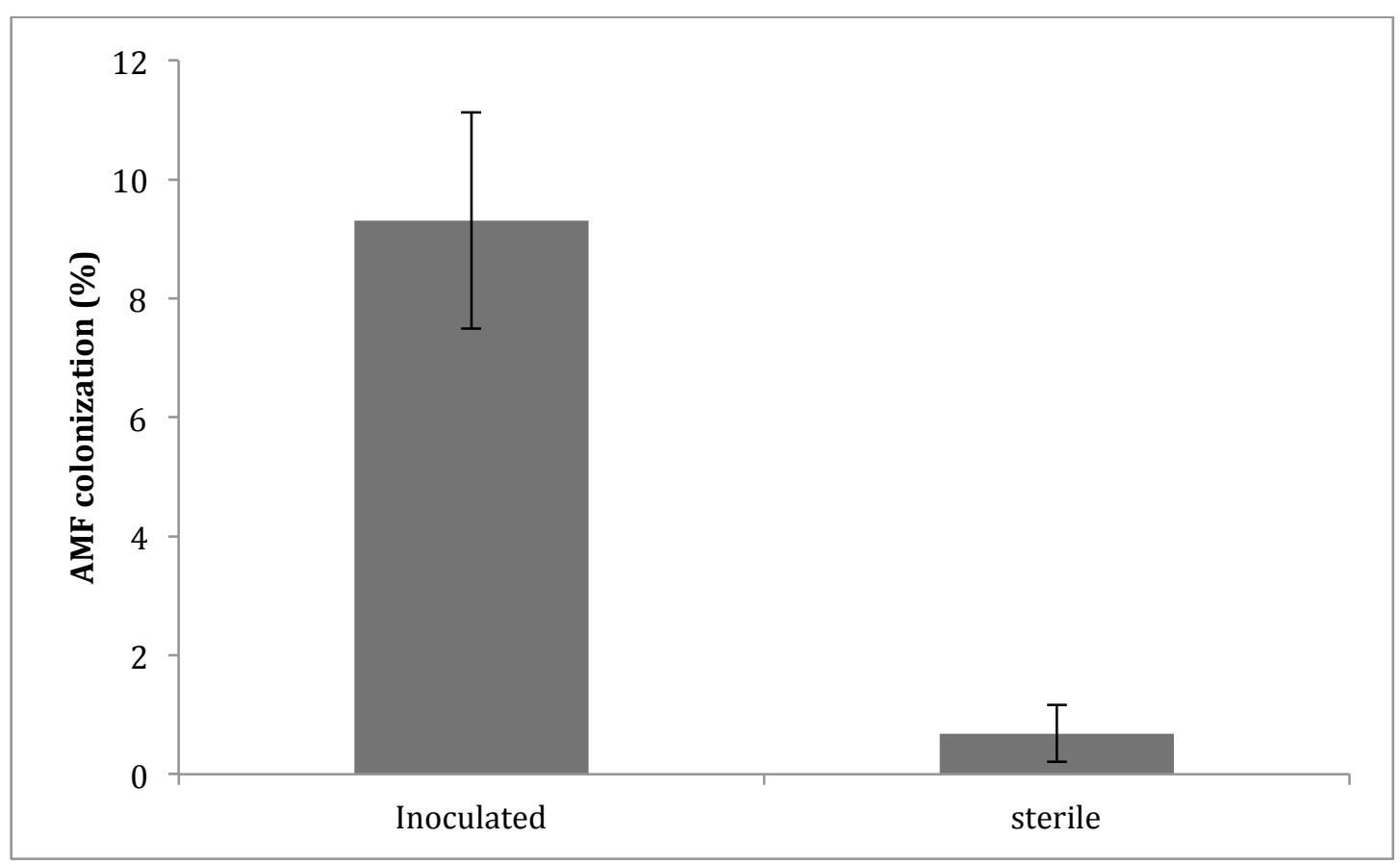

Figure 2.6. Percent colonization by arbuscular mycorrhizal fungi for inoculated and sterile plants for 120 day harvest. Error bars represent standard error. 


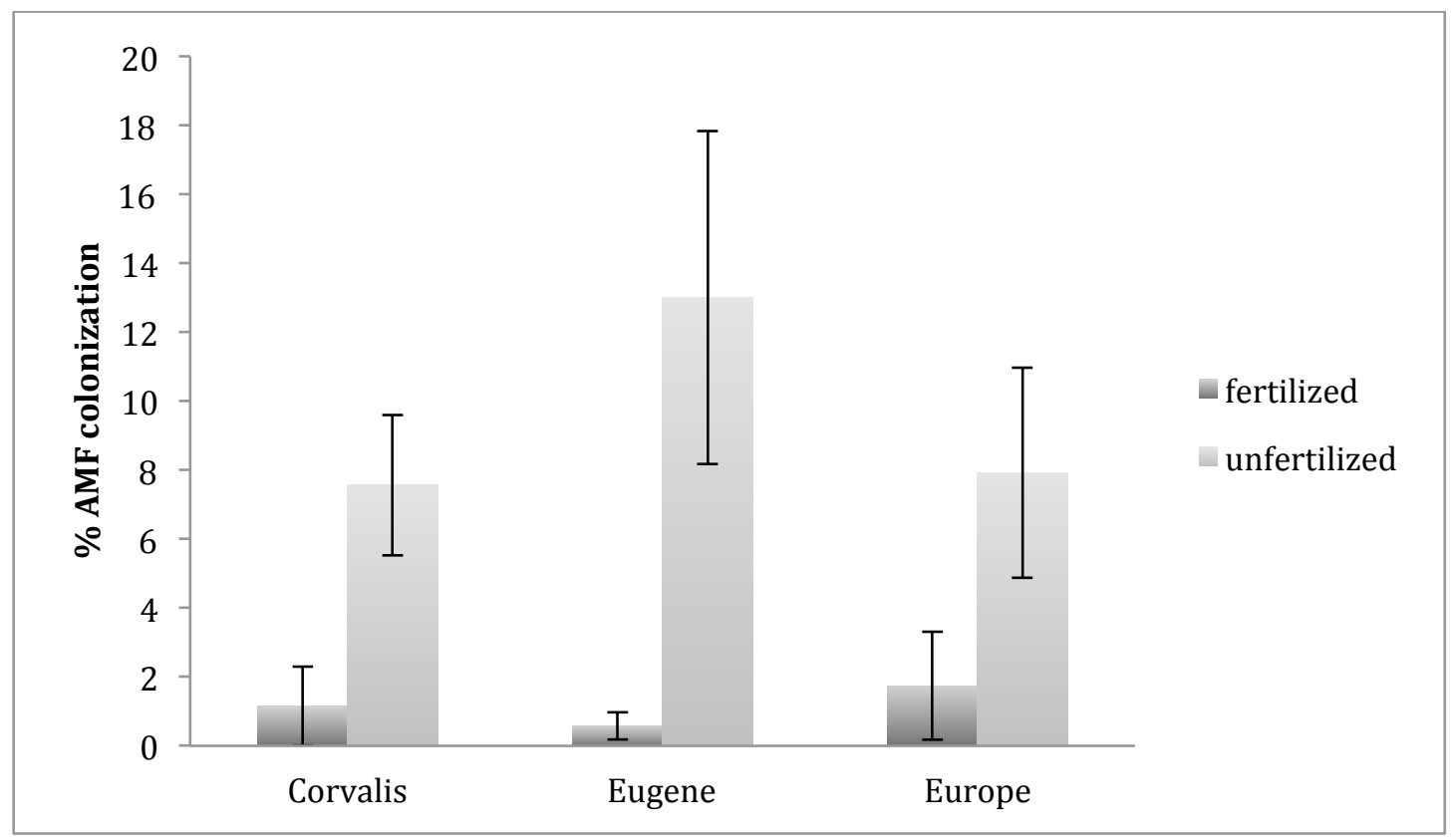

Figure 2.7. Percent roots colonized by arbuscular mycorrhizal fungi for fertilized and unfertilized plants for each region (Corvallis, Eugene, and Europe) for 120 day harvest. Error bars represent standard error. 


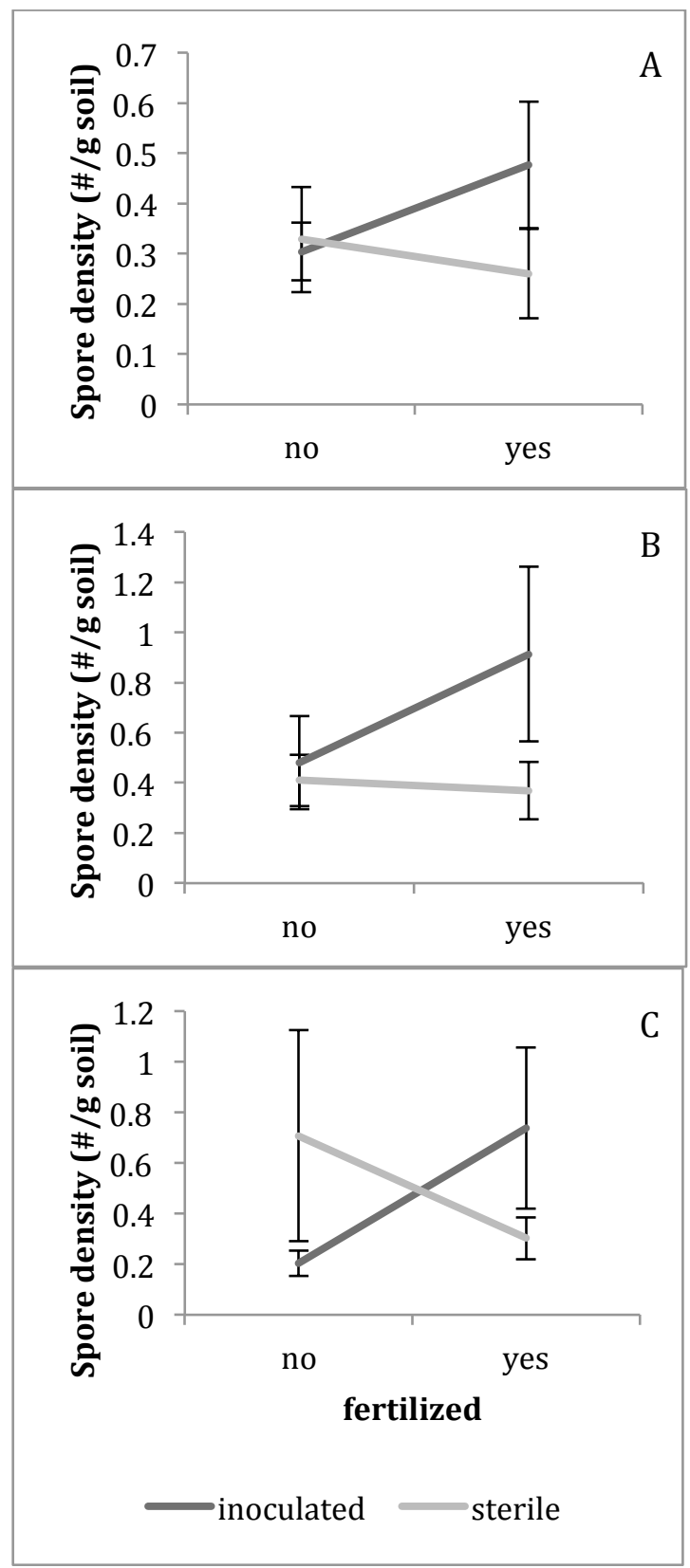

Figure 2.8. The change in spore densities (spore number/g soil) between fertilized and unfertilized, sterile and inoculated plants from Corvallis (A), Eugene (B), and Europe (C) for 90 day harvest. Error bars represent standard error. 


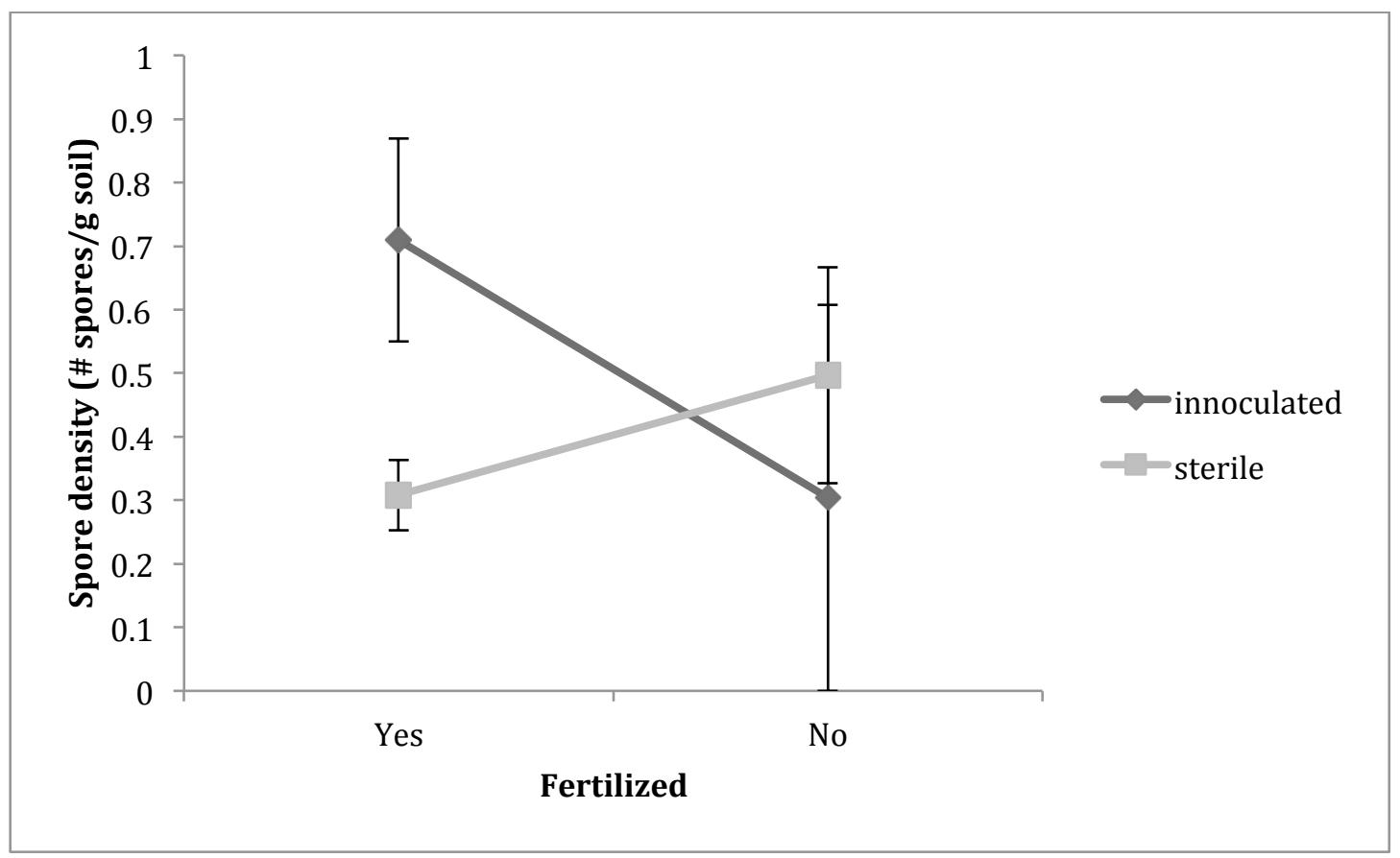

Figure 2.9. Arbuscular mycorrhizal spore density of soil (spore number/g soil) for fertilized, unfertilized, sterile, and inoculated plants across all regions for 90 day harvest. 


\section{References}

Aarrestad PA. 2000. Plant communities in broad-leaved deciduous forests in Hordaland county, Western Norway. Nordic Journal of Botany 20:449-466.

An GH, Kobayashi S, Enoki H, Sonobe K, Muraki M, Karasawa T, Ezawa T. 2010. How does arbuscular mycorrhizal colonization vary with host plant genotype? An example based on maize (Zea mays) germplasms. Plant and Soil 327:441-453.

Antunes PM, Lehmann A, Hart MM, Baumecker M, Rillig MC. 2012. Long-term effects of soil nutrient deficiency on arbuscular mycorrhizal communities. Functional Ecology 26:532-540.

Barker SJ, Duplessis S, Tagu D. 2002. The application of genetic approaches for investigations of mycorrhizal symbioses. Plant and Soil 244:85-95.

Bethlenfalvay GJ, Reyessolis MG, Camel SB, Ferreracerrato R. 1991. Nutrient transfer between the root zones of soybean and maize plants connected by a common mycorrhizal mycelium. Physiologia Plantarum 82:423-432.

Brkljacic J, Grotewold E, Scholl R, Mockler T, Garvin DF, Vain P, Brutnell T, Sibout R, Bevan M, Budak H, et al. 2011. Brachypodium as a Model for the Grasses: Today and the Future. Plant Physiology 157:3-13.

Bronstein JL. 1994. Conditional outcomes in mutualistic interactions. Trends in Ecology \& Evolution 9:214-217.

Callaway RM, Cipollini D, Barto K, Thelen GC, Hallett SG, Prati D, Stinson K, Klironomos J. 2008. Novel weapons: Invasive plant suppresses fungal mutualists in America but not in its native Europe. Ecology 89:1043-1055.

Callaway RM, DeLuca TH, Belliveau WM. 1999. Biological-control herbivores may increase competitive ability of the noxious weed Centaurea maculosa. Ecology 80:1196-1201.

Callaway RM, Thelen GC, Barth S, Ramsey PW, Gannon JE. 2004. Soil fungi alter interactions between the invader Centaurea maculosa and North American natives. Ecology 85:1062-1071.

Catford JA, Jansson R, Nilsson C. 2009. Reducing redundancy in invasion ecology by integrating hypotheses into a single theoretical framework. Diversity and Distributions 15:22-40.

CDFA. 2009. California department of food and agriculture plant quarantine manual. 
Chambers K. 1966. Notes on some grasses of the Pacific Coast. Madroño 18:250-251.

Cheng XM, Baumgartner K. 2004. Arbuscular mycorrhizal fungi-mediated nitrogen transfer from vineyard cover crops to grapevines. Biology and Fertility of Soils 40:406-412.

Correa A, Cruz C, Perez-Tienda J, Ferrol N. 2014. Shedding light onto nutrient responses of arbuscular mycorrhizal plants: Nutrient interactions may lead to unpredicted outcomes of the symbiosis. Plant Science 221:29-41.

Cumming JR, Kelly CN. 2007. Pinus virginiana invasion influences soils and arbuscular mycorrhizae of a serpentine grassland. Journal of the Torrey Botanical Society 134:63-73.

Daleo P, Alberti J, Canepuccia A, Escapa M, Fanjul E, Silliman BR, Bertness MD, Iribarne 0. 2008. Mycorrhizal fungi determine salt-marsh plant zonation depending on nutrient supply. Journal of Ecology 96:431-437.

Dantonio CM, Vitousek PM. 1992. Biological invasions by exotic grasses, the grass fire cycle, and global change. Annual Review of Ecology and Systematics 23:6387.

Douds DD. 1994. RELATIONSHIP BETWEEN HYPHAL AND ARBUSCULAR COLONIZATION AND SPORULATION IN A MYCORRHIZA OF PASPALUMNOTATUM FLUGGE. New Phytologist 126:233-237.

Douds DD, Chaney WR. 1982. Correlation of fungal morphology and development to host growth in a green ash mycorrhiza. New Phytologist 92:519-526.

Douds DD, Galvez L, Becard G, Kapulnik Y. 1998. Regulation of arbuscular mycorrhizal development by plant host and fungus species in alfalfa. New Phytologist 138:27-35.

Draper J, Mur LAJ, Jenkins G, Ghosh-Biswas GC, Bablak P, Hasterok R, Routledge APM. 2001. Brachypodium distachyon. A new model system for functional genomics in grasses. Plant Physiology 127:1539-1555.

Dunstan WA, Dell B, Malajczuk N. 1998. The diversity of ectomycorrhizal fungi associated with introduced Pinus spp in the southern hemisphere, with particular reference to western Australia. Mycorrhiza 8:71-79.

Endresz G, Somodi I, Kalapos T. 2013. Arbuscular mycorrhizal colonisation of roots of grass species differing in invasiveness. Community Ecology 14:67-76. 
Fellbaum CR, Mensah JA, Cloos AJ, Strahan GE, Pfeffer PE, Kiers ET, Bucking H. 2014. Fungal nutrient allocation in common mycorrhizal networks is regulated by the carbon source strength of individual host plants. New Phytologist 203:646-656.

Gehring CA, Mueller RC, Whitham TG. 2006. Environmental and genetic effects on the formation of ectomycorrhizal and arbuscular mycorrhizal associations in cottonwoods. Oecologia 149:158-164.

Gerdemann JW, Nicolson TH. 1963. Spores of mycorrhizal Endogone species extracted from soil by wet sieving and decanting. Transactions of the British Mycological Society 46:235-244.

Goodwin J. 1992. The role of mycorrhizal fungi in competitive interactions among native bunchgrasses and alien weeds - a review and synthesis. Northwest Science 66:251-260.

Grman E. 2012. Plant species differ in their ability to reduce allocation to nonbeneficial arbuscular mycorrhizal fungi. Ecology 93:711-718.

Grman E, Robinson TMP. 2013. Resource availability and imbalance affect plantmycorrhizal interactions: a field test of three hypotheses. Ecology 94:62-71.

Grman E, Robinson TMP, Klausmeier CA. 2012. Ecological specialization and trade affect the outcome of negotiations in mutualism. American Naturalist 179:567581.

Grman E, Suding KN. 2010. Within-year soil legacies contribute to strong priority effects of exotics on native California grassland communities. Restoration Ecology 18:664-670.

Hallett SG. 2006. Dislocation from coevolved relationships: a unifying theory for plant invasion and naturalization? Weed Science 54:282-290.

Hawkes CV. 2003. Nitrogen cycling mediated by biological soil crusts and arbuscular mycorrhizal fungi. Ecology 84:1553-1562.

Hawkes CV, Belnap J, D'Antonio C, Firestone MK. 2006. Arbuscular mycorrhizal assemblages in native plant roots change in the presence of invasive exotic grasses. Plant and Soil 281:369-380.

He XH, Critchley C, Bledsoe C. 2003. Nitrogen transfer within and between plants through common mycorrhizal networks (CMNs). Critical Reviews in Plant Sciences 22:531-567. 
Hoeksema JD, Chaudhary VB, Gehring CA, Johnson NC, Karst J, Koide RT, Pringle A, Zabinski C, Bever JD, Moore JC, et al. 2010. A meta-analysis of contextdependency in plant response to inoculation with mycorrhizal fungi. Ecology Letters 13:394-407.

Holten JI. 1980. Distribution and ecology of Brachypodium sylvaticum, Bromus benekeni and Festuca altissima in Central Norway. Blyttia 38:137-144.

INVAM. Morgantown, WV. Available from: http://invam.caf.wvu.edu

Ji BM, Bentivenga SP, Casper BB. 2012. Comparisons of AM fungal spore communities with the same hosts but different soil chemistries over local and geographic scales. Oecologia 168:187-197.

Johnson D, Anderson IC, Williams A, Whitlock R, Grime JP. 2010. Plant genotypic diversity does not beget root-fungal species diversity. Plant and Soil 336:107111.

Johnson NC. 1993. Can fertilization of soil select less mutualistic mycorrhizae. Ecological Applications 3:749-757.

Johnson NC, Graham JH. 2013. The continuum concept remains a useful framework for studying mycorrhizal functioning. Plant and Soil 363:411-419.

Johnson NC, Graham JH, Smith FA. 1997. Functioning of mycorrhizal associations along the mutualism-parasitism continuum. New Phytologist 135:575-586.

Jordan NR, Aldrich-Wolfe L, Huerd SC, Larson DL, Muehlbauer G. 2012. Soiloccupancy effects of invasive and native grassland plant species on composition and diversity of mycorrhizal associations. Invasive Plant Science and Management 5:494-505.

Jordan NR, Larson DL, Huerd SC. 2011. Evidence of qualitative differences between soil-occupancy effects of invasive vs. native grassland plant species. Invasive Plant Science and Management 4:11-21.

Kahiluoto H, Ketoja E, Vestberg M, Saarela I. 2001. Promotion of AM utilization through reduced P fertilization 2. Field studies. Plant and Soil 231:65-79.

Karasawa T, Hodge A, Fitter AH. 2012. Growth, respiration and nutrient acquisition by the arbuscular mycorrhizal fungus Glomus mosseae and its host plant Plantago lanceolata in cooled soil. Plant Cell and Environment 35:819-828. 
Kaye TN, Blakeley-Smith M. 2006. False-brome (Brachypodium sylvaticum). In: Boersma PD, Reichard SE, Buren ANv, editors. Invasive species in the Pacific Northwest. Seattle: University of Washington Press. p. 80-81.

Kiers ET, Duhamel M, Beesetty Y, Mensah JA, Franken O, Verbruggen E, Fellbaum CR, Kowalchuk GA, Hart MM, Bago A, et al. 2011. Reciprocal rewards stabilize cooperation in the mycorrhizal symbiosis. Science 333:880-882.

Kirby KJ, Thomas RC. 2000. Changes in the ground flora in Wytham Woods, southern England from 1974 to 1991 - implications for nature conservation. Journal of Vegetation Science 11:871-880.

Klironomos JN. 2002a. Another form of bias in conservation research. Science 298:749-749.

Klironomos JN. 2002b. Feedback with soil biota contributes to plant rarity and invasiveness in communities. Nature 417:67-70.

Klironomos JN. 2003. Variation in plant response to native and exotic arbuscular mycorrhizal fungi. Ecology 84:2292-2301.

Kulmatiski A, Beard KH. 2011. Long-term plant growth legacies overwhelm shortterm plant growth effects on soil microbial community structure. Soil Biology \& Biochemistry 43:823-830.

Lee CE. unpublished data. A field survey of arbuscular mycorrhizal fungal abundance between invasive Brachypodium sylvaticum and native Elymus glaucus. In. Portland, OR: Portland State University.

Linderman RG, Davis EA. 2004. Varied response of marigold (Tagetes spp.) genotypes to inoculation with different arbuscular mycorrhizal fungi. Scientia Horticulturae 99:67-78.

Mack RN, Simberloff D, Lonsdale WM, Evans H, Clout M, Bazzaz FA. 2000. Biotic invasions: Causes, epidemiology, global consequences, and control. Ecological Applications 10:689-710.

Mangan SA, Herre EA, Bever JD. 2010. Specificity between Neotropical tree seedlings and their fungal mutualists leads to plant-soil feedback. Ecology 91:2594-2603.

Marchini GL, Cruzan MB. in review. The consequences of gene diversity and nitrogen deposition for competitive success of the newly invasive grass Brachypodium sylvaticum. In. Portland, OR: Portland State University. 
Marler MJ, Zabinski CA, Callaway RM. 1999. Mycorrhizae indirectly enhance competitive effects of an invasive forb on a native bunchgrass. Ecology 80:11801186.

Marler MJ, Zabinski CA, Wojtowicz T, Callaway RM. 1999. Mycorrhizae and fine root dynamics of Centaurea maculosa and native bunchgrasses in western Montana. Northwest Science 73:217-224.

McGonigle TP, Miller MH, Evans DG, Fairchild GL, Swan JA. 1990. A new method which gives an objective-measure of colonization of roots by vesicular arbuscular mycorrhizal fungi. New Phytologist 115:495-501.

McKenney MC, Lindsey DL. 1987. Improved method for quantifying endomycorrhizal fungi spores from soil. Mycologia 79:779-782.

Meier R, Charvat I. 1992. Peridial development in Glomus mosseae (Glomaceae). American Journal of Botany 79:928-936.

Meiman PJ, Redente EF, Paschke MW. 2006. The role of the native soil community in the invasion ecology of spotted (Centaurea maculosa auct. non Lam.) and diffuse (Centaurea diffusa Lam.) knapweed. Applied Soil Ecology 32:77-88.

Meinhardt KA, Gehring CA. 2012. Disrupting mycorrhizal mutualisms: a potential mechanism by which exotic tamarisk outcompetes native cottonwoods. Ecological Applications 22:532-549.

Miller BM, Aitken RJ, Oldham MJ, Reznicek AA. 2011. Slender False Brome (Brachypodium sylvaticum, Poaceae), an invasive grass new to Ontario, Canada. Canadian Field-Naturalist 125:235-240.

Mitchell CE, Agrawal AA, Bever JD, Gilbert GS, Hufbauer RA, Klironomos JN, Maron JL, Morris WF, Parker IM, Power AG, et al. 2006. Biotic interactions and plant invasions. Ecology Letters 9:726-740.

Morcom NF, Woelkerling J. 2000. A critical interpretation of coralline-coralline (Corallinales, Rhodophyta) and coralline-other plant interactions. Cryptogamie Algologie 21:1-31.

Mur LAJ, Allainguillaume J, Catalan P, Hasterok R, Jenkins G, Lesniewska K, Thomas I, Vogel J. 2011. Exploiting the Brachypodium Tool Box in cereal and grass research. New Phytologist 191:334-347.

Neuhauser C, Fargione JE. 2004. A mutualisim-parasitism continuum model and its application to plant-mycorrhizae interactions. Ecological Modelling 177:337-352. 
Nijjer S, Rogers WE, Lee CTA, Siemann E. 2008. The effects of soil biota and fertilization on the success of Sapium sebiferum. Applied Soil Ecology 38:1-11.

Washington State noxious weed control borad. [Internet]. 2009. Available from http://www.nwcb.wa.gov/.

ODA. 2009. Oregon department of agriculture plant division, noxious weed control, Oregon, USA.

Panwar V, Meghvansi MK, Siddiqui S. 2011. Short-term temporal variation in sporulation dynamics of arbuscular mycorrhizal (AM) fungi and physicochemical edaphic properties of wheat rhizosphere. Saudi Journal of Biological Sciences 18:247-254.

Pearson JN, Jakobsen I. 1993. Symbiotic exchange of carbon and phosphorus between cucumber and 3 arbuscular mycorrhizal fungi. New Phytologist 124:481-488.

Peraldi A, Griffe LL, Burt C, McGrann GRD, Nicholson P. 2014. Brachypodium distachyon exhibits compatible interactions with Oculimacula spp. and Ramularia collo-cygni, providing the first pathosystem model to study eyespot and ramularia leaf spot diseases. Plant Pathology 63:554-562.

Phillips JM, Hayman DS. 1970. Improved procedures for clearing roots and staining parasitic and vesicular-arbuscular mycorrhizal fungi for rapid assessment of infection. Transactions of the British Mycological Society 55:158-\&.

Pimentel D, Zuniga R, Morrison D. 2005. Update on the environmental and economic costs associated with alien-invasive species in the United States. Ecological Economics 52:273-288.

Porter SS, Stanton ML, Rice KJ. 2011. Mutualism and adaptive divergence: coinvasion of a heterogeneous grassland by an exotic legume-rhizobium symbiosis. Plos One 6.

Ramakrishnan AP, Musial T, Cruzan MB. 2010. Shifting dispersal modes at an expanding species' range margin. Molecular Ecology 19:1134-1146.

Ramakrishnan AP, Rosenthal DM, Musial T, Cruzan MB. 2008. Isolation and characterization of nine microsatellite markers for Brachypodium sylvaticum (Huds.) Beauv., a recently invasive grass species in Oregon. Molecular Ecology Resources 8:1297-1299. 
Reinhart KO, Callaway RM. 2006. Soil biota and invasive plants. New Phytologist 170:445-457.

Richardson DM, Allsopp N, D'Antonio CM, Milton SJ, Rejmanek M. 2000. Plant invasions - the role of mutualisms. Biological Reviews 75:65-93.

Richardson DM, Pysek P. 2006. Plant invasions: merging the concepts of species invasiveness and community invasibility. Progress in Physical Geography 30:409-431.

Rosenthal DM, Ramakrishnan AP, Cruzan MB. 2008. Evidence for multiple sources of invasion and intraspecific hybridization in Brachypodium sylvaticum (Hudson) Beauv. in North America. Molecular Ecology 17:4657-4669.

Roy BA. 2010. Brachypodium sylvaticum. In. Invasive Species Compedium. Wellingford, United Kingdom: CABI.

Sanon A, Beguiristain T, Cebron A, Berthelin J, Ndoye I, Leyval C, Sylla S, Duponnois R. 2009. Changes in soil diversity and global activities following invasions of the exotic invasive plant, Amaranthus viridis L., decrease the growth of native sahelian Acacia species. Fems Microbiology Ecology 70:118-131.

Sanon A, Beguiristain T, Cebron A, Berthelin J, Sylla SN, Duponnois R. 2012. Differences in nutrient availability and mycorrhizal infectivity in soils invaded by an exotic plant negatively influence the development of indigenous Acacia species. Journal of Environmental Management 95:S275-S279.

Schlaepfer MA, Sherman PW, Blossey B, Runge MC. 2005. Introduced species as evolutionary traps. Ecology Letters 8:241-246.

Schussler A, Schwarzott D, Walker C. 2001. A new fungal phylum, the Glomeromycota: phylogeny and evolution. Mycological Research 105:1413-1421.

Schwab SM, Menge JA, Tinker PB. 1991. Regulation of nutrient transfer between host and fungus in vesicular arbuscular mycorrhizas. New Phytologist 117:387398.

Schwartz MW, Hoeksema JD. 1998. Specialization and resource trade: Biological markets as a model of mutualisms. Ecology 79:1029-1038.

Seifert EK, Bever JD, Maron JL. 2009. Evidence for the evolution of reduced mycorrhizal dependence during plant invasion. Ecology 90:1055-1062. 
Simard SW, Durall DM. 2004. Mycorrhizal networks: a review of their extent, function, and importance. Canadian Journal of Botany-Revue Canadienne De Botanique 82:1140-1165.

Smith SE, Read DJ. 2008. Mycorrhizal Symbiosis, 3rd Edition.

Steinwand MA, Young HA, Bragg JN, Tobias CM, Vogel JP. 2013. Brachypodium sylvaticum, a Model for Perennial Grasses: Transformation and Inbred Line Development. Plos One 8.

Sturmer SL, Siqueira JO. 2011. Species richness and spore abundance of arbuscular mycorrhizal fungi across distinct land uses in Western Brazilian Amazon. Mycorrhiza 21:255-267.

Sylvia DM, Neal LH. 1990. Nitrogen affects the phosphorus response of VA mycorrhiza. New Phytologist 115:303-310.

Treseder KK, Allen MF. 2002. Direct nitrogen and phosphorus limitation of arbuscular mycorrhizal fungi: a model and field test. New Phytologist 155:507515.

van der Heijden MGA, Streitwolf-Engel R, Riedl R, Siegrist S, Neudecker A, Ineichen K, Boller T, Wiemken A, Sanders IR. 2006. The mycorrhizal contribution to plant productivity, plant nutrition and soil structure in experimental grassland. New Phytologist 172:739-752.

van der Putten WH, Klironomos JN, Wardle DA. 2007. Microbial ecology of biological invasions. Isme Journal 1:28-37.

Velazquez S, Cabello M. 2011. Occurrence and diversity of arbuscular mycorrhizal fungi in trap cultures from El Palmar National Park soils. European Journal of Soil Biology 47:230-235.

Vogelsang KM, Bever JD. 2009. Mycorrhizal densities decline in association with nonnative plants and contribute to plant invasion. Ecology 90:399-407.

Wang B, Qiu YL. 2006. Phylogenetic distribution and evolution of mycorrhizas in land plants. Mycorrhiza 16:299-363.

Wilson GWT, Hickman KR, Williamson MM. 2012. Invasive warm-season grasses reduce mycorrhizal root colonization and biomass production of native prairie grasses. Mycorrhiza 22:327-336. 
Workman RE, Cruzan MB. in review. Adjacent invaded and non-invaded range mycorrhizae differentially impact success of invasive grass Brachypodium sylvaticum. In. Portland, OR: Portland State University.

Workman RE, Cruzan MB. in preparation. Common mycelial networks impact belowground competition in an invasive grass. In. Portland: Portland State University.

Yang Q, Carrillo J, Jin HY, Shang L, Hovick SM, Nijjer S, Gabler CA, Li B, Siemann E. 2013. Plant-soil biota interactions of an invasive species in. its native and introduced ranges: Implications for invasion success. Soil Biology \& Biochemistry 65:78-85.

Zhang Q, Yang RY, Tang JJ, Yang HS, Hu SJ, Chen X. 2010. Positive feedback between mycorrhizal fungi and plants influences plant invasion success and resistance to invasion. Plos One 5.

Zhang Q, Yao LJ, Yang RY, Yang XY, Tang JJ, Chen X. 2007. Potential allelopathic effects of an invasive species Solidago canadensis on the mycorrhizae of native plant species. Allelopathy Journal 20:71-77. 